This document is the accepted manuscript version of the following article:
K. Schöller, C. Toncelli, J. Experton, S. Widmer, D. Rentsch, A. Vetushka, C. Martin, M. Heuberger, C. E. Housecroft, E.C. Constable, L.F. Boesel, L.J. Scherer (2016). 2,2':6',2"- Terpyridine-functionalized redox-responsive hydrogels as a platform for multi responsive amphiphilic polymer membranes. RSC Advances, 6(100), 97921-97930. http://doi.org/10.1039/C6RA23677D

\title{
2,2':6',2"-Terpyridine-functionalized redox-responsive hydrogels as a platform for multi responsive amphiphilic polymer membranes
}

\begin{abstract}
Katrin Schöller ${ }^{a}{ }^{\dagger}$, Claudio Toncelli ${ }^{a}{ }^{\dagger} \dagger$, Juliette Experton ${ }^{a}$, Susanne Widmer ${ }^{a}$, Daniel Rentsch ${ }^{b}$, Aliaksei Vetushkac, Colin J. Martin ${ }^{d}$, Manfred Heuberger ${ }^{a}$, Catherine. E. Housecroft, $^{d}$ Edwin C. Constable $^{d}$, Luciano F. Boesel ${ }^{\mathrm{a}, *}$, Lukas J. Scherer $^{\mathrm{a}}$

Nanophase-separated amphiphilic polymer co-networks are ideally suited as responsive membranes due to their stable cocontinuous structure. Their functionalization with redox-responsive $2,2^{\prime}: 6^{\prime}, 2^{\prime \prime}$-terpyridine-metal complexes and lightresponsive spiropyran derivatives leads to a novel material with tunable optical, redox and permeability properties. The versatility of the system in complexing various metal ions, such as cobalt or iron at different concentrations, results in a perfect monitoring over the degree of crosslinking of the hydrophilic poly(2-hydroxyethyl acrylate) channels. The reversibility of the complexation, the redox state of the metal and the isomerization to the merocyanine form upon UV illumination was evidenced by cyclic voltammetry, UV-Vis and permeability measurements under sequential conditions. Thus, the membrane provides light and redox addressable functionalities due to its adjustable and mechanically stable hydrogel network.
\end{abstract}

\section{Introduction}

Amphiphilic co-networks (APCNs) have been drawing the interest of scientists from different fields due to their peculiar polymer platform which consists of interconnected hydrophilic/hydrophobic phases of co-continuous morphology ${ }^{1}$. APCNs are able to swell and form gel structures both in water and organic phases ${ }^{2}$. The versatility of the synthesis approach and the variety of functional monomers, bi and poly-functional cross-linkers allows fine tuning of the overall network properties with phase separation occurring even at the nanoscale ${ }^{3}$. The modulation of such properties allows the targeting of defined swelling in aqueous and organic solvents, permeability of gas and host molecules as well as entrapment and localized diffusion of host molecules in targeted areas ${ }^{1}$. Hence, these co-networks are generally employed in the synthesis of drug-delivery systems ${ }^{4}$, scaffolds for tissue engineering ${ }^{5}$, biocatalysts and nanoreactors ${ }^{6}$, contact lenses ${ }^{7}$, biosensors ${ }^{8}$ and body implants ${ }^{9}$.

In particular, application in tissue engineering and drug delivery not only aim at the above mentioned properties, but it

\footnotetext{
a. Empa, Swiss Federal Laboratories for Materials Science and Technology, Lerchenfeldstrasse 5, 9014 St. Gallen, Switzerland

b. Empa, Swiss Federal Laboratories for Materials Science and Technology, Überlandstrasse 129, 8600 Dübendorf, Switzerland

c. Laboratory of Nanostructures and Nanomaterials, Institute of Physics AS CR, Cukrovarnicka 10, 16200 Prague 6, Czech Republic

d. Department of Chemistry, University of Basel, Spitalstrasse 51, 4056 Basel, Switzerland

† These authors contributed equally.

Electronic Supplementary Information (ESI) available:
}

is also desirable to change these properties in response to an external stimulus. Thus, the host matrix may itself control and tune the features of such "smart" materials through local shifts in $\mathrm{pH}$, ionic strength, temperature or oxidant level ${ }^{10}$. In addition, in the case of drug-delivery nanocarriers, external stimuli such as magnetic, light, ultrasonic and electric fields could be utilized for remote switching of network hydrophilicity, local heat control and guidance of the drug content in the targeted area ${ }^{11}$. The stimuli not only serve to selectively release the drug content in the designated area, but it might alter the pharmaco-kinetics in order to attain a linear diffusion and therefore prolong the controlled release rate for a spatial, temporal as well as dose control precision ${ }^{12}$.

Dual and multi-stimuli responsiveness have been actively investigated in an effort to further improve the precision of the response and enhance the switching window ${ }^{13}$.

Light-responsive materials have been used to remotely trigger the hydrogel hydrophilicity via immobilization of azobenzene $^{14}$, stilbene ${ }^{15}$, diarylethene ${ }^{16}$, fulgides $^{17}$ and spiropyrans. The latter has been widely studied due to the range of stimuli able to induce its reversible isomerization, which, besides light, also includes different solvents, metal ions, acids and bases, temperature, redox potential, and mechanical force ${ }^{18-22}$.

Redox sensitive polymeric carriers are appealing for triggered drug delivery as cytosol and cell nuclei contain 4-400 times higher concentration of reducing glutathione (GSH) tripeptide relative to body fluids $(0.5-10 \mathrm{mM} \text { versus } 2-20 \mathrm{mM} \mathrm{GSH})^{23}$. Moreover, in vivo research has demonstrated that in mice 4- 
fold higher GSH concentrations are present in tumor tissues compared to non-carcinogenic ones ${ }^{24}$.

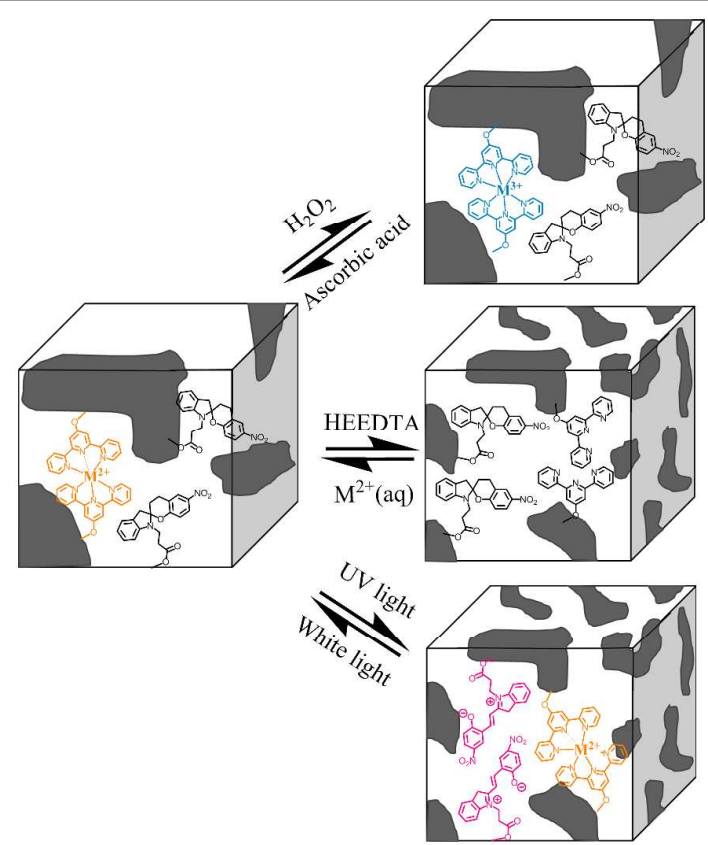

Scheme 1. Possible responses of multi stimuli-responsive membranes from $2,2^{\prime}: 6^{\prime}, 2^{\prime \prime}$ terpyridine (TP1) and spiropyran side-chain functionalized amphiphilic polymer networks (orange colour: $\mathrm{M}^{2+/} \mathrm{TP} 1$ complex, blue colour: $\mathrm{M}^{3+/} \mathrm{TP} 1$ complex, pink colour: spiropyran in the merocyanine form).

On the other hand, oxidation-responsive nanocarriers might liberate their payload when elevated levels of reactive oxygen species, including superoxide, hydrogen peroxide, and hydroxide radicals, are present, since such levels are often observed in cellular inflammation as part of the non-specific immune reaction ${ }^{25}$

In the last decade, metal-induced cross-linking has become a promising alternative to the more popular redox responsive materials bearing di-sulfide or di-selenide linkages ${ }^{26}$. Indeed, metallo-supramolecular polymers not only exhibited structural integrity in aqueous solution under different conditions $(\mathrm{pH}$ and temperature), but provide the possibility of precisely controlled release profiles of their encapsulated hydrophobic guest molecules via the combination of varying stimuli ${ }^{27}$.

Although ferrocenyl moieties are the most investigated metalorganic frameworks (MOFs), the exclusive motif of $\mathrm{Fe}(\mathrm{II}) / \mathrm{Fe}(\mathrm{III})$ redox couple does not suffice for a fine-tuning of the permeability and swelling properties ${ }^{28}$. Benzimidazole moieties ${ }^{29}$, carboxylic moieties in benzene tricarboxylic ligands $^{30}$ or poly(acrylic acids) $)^{31}$ and amino groups in chitosan ${ }^{32}$ offer a wider range of metal ion redox switches that can be utilized for such purposes. However, these mono-dentate ligands are often characterized by a weak coordinating bond, which might hamper the gel stability outside the target delivery area. Pyridine ligands, such as pyridine ${ }^{33}, 2,2^{\prime}-$ bipyridine $^{34}$ and $2,2^{\prime}: 6^{\prime}, 2^{\prime \prime}$-terpyridine ${ }^{35}$ (tpy) offer remarkably stable metal complexes. In particular, one of the first redox switches for biomedical applications employed the redox couple $\mathrm{Ru}(\mathrm{II}) / \mathrm{Ru}(\mathrm{III})$ in the presence of tpy. ${ }^{36}$

However, as demonstrated by Meier et al. ${ }^{37}$, other metal ions could be employed for MOFs assembly, with the relative binding strength (i.e. related to the metal-induced cross-linked network stability) following this sequence: $\mathrm{Co}>\mathrm{Ru}>\mathrm{Fe}>\mathrm{Ni}>$ $\mathrm{Cu}>\mathrm{Mn}>\mathrm{Cd}$.

In the case of the $\mathrm{Co}(\mathrm{II}) / \mathrm{Co}(\mathrm{III})^{38,39}$ and $\mathrm{Fe}(\mathrm{II}) / \mathrm{Fe}(\mathrm{III})^{40}$ couples, the redox change has proved to impart different optical, mechanical and swelling/permeability properties.

In this paper, a dual responsive system based on spiropyran and terpyridine ligands is hereby synthesized by covalent immobilization on APCN co-network membrane constituted of poly((trimethylsilyl)oxyethylmethacrylate) (poly(TMS-HEA)) and a poly(dimethylsiloxane) dimethacrylate (PDMS-DMA) as cross-linker.

The optical and mechanical behavior during switching from non-complexed to complexed state in the presence of $\mathrm{Co}$ (II) metal ions was characterized by UV-Vis measurements and atomic force microscopy (AFM). De-complexation was attained by the competitive ligation of $\mathrm{Co}$ (II) with hydroxyethyl(ethylenediaminetriacetic acid) (HEEDTA) (Scheme 1).

The different complexation/de-complexation and redox states combined with the light switch induced by the presence of spiropyran moieties in the APCNs were evaluated on the basis of their morphological, optical and redox properties.

\section{Experimental section}

\section{Materials}

Microscope glass slides from Thermo Scientific were used as support and cover for the membrane production. Selfadhesive tape (Tesafilm universal, transparent) was used as spacer unit between the two glass slides. 2((trimethylsilyl)oxy)ethyl acrylate (TMS-HEA) and $\alpha, \omega$ methacryloxypropyl poly(dimethylsiloxane) (PDMS-DMA), 48 to 75 monomer units) were purchased from ABCR. TMS-HEA, acryloyl chloride (Sigma-Aldrich) and 2-hydroxyethylacrylate (Sigma-Aldrich) were distilled under reduced pressure before usage and stored in the freezer for no more than one month. Irgacure 819 was provided by BASF.

Bromine, 2,3,3-trimethylindolenine, 3-iodopropionic acid, 4dimethylaminopyridine, $N, N^{\prime}$-dicyclohexylcarbodiimide, 4'Chloro-2,2':6',2'-terpyridine, piperidine, 2-hydroxy-5nitrobenzaldehyde, trimethylamine, 1,6-hexandiol, hydrogen peroxide $30 \mathrm{wt}$-\% in water, 2-butanone, L-ascorbic acid, iron(II) and cobalt(II) chloride tetrahydrates were purchased from Sigma-Aldrich.

Hexane was purchased from Biosolve. Tetrahydrofuran (THF), dimethylsulfoxide (DMSO), toluene, methanol and dichloromethane were purchased from Fisher Chemicals. Dichloromethane extra-dry and magnesium sulfate were purchased by Acros Organics. Caffeine and potassium carbonate anhydrous and potassium hydroxide in pellets were 
purchased from Fluka. Trilon D Liquid, an aqueous solution of hydroxyethyl(ethylenediaminetriacetic acid) (HEEDTA) (39.041.0 wt-\%) was kindly provided by BASF. Unless stated otherwise, all chemicals were used as purchased without further purification and distilled water from the in-house supply was used.

\section{Preparation of monomer solutions}

Spirobenzopyran covalently immobilized on an acrylate moiety (SP) (Scheme 2) was synthesized as reported earlier by our group $^{20}$ (36\% yield). The tpy ligand directly anchored to an acrylate moiety via an aliphatic spacer (Scheme 2) was synthesized according to literature in $49 \%$ overall yield. ${ }^{41}$ Detailed descriptions of analytical characterization of the reactants can be found in the Supplementary Information.

\section{Complexation/de-complexation studies of TP1}

UV-Vis spectra of solutions and membranes (in the switching studies) were performed on a Biotek Synergy $\mathrm{Mx}$ microplate reader. The characterization of monomers in solution after multiple oxidation/reduction cycles was performed with 4 solutions each containing $1.83 \mathrm{mg}$ TP1 and $0.44 \mathrm{mg} \mathrm{CoCl} 2.4 \mathrm{H}_{2} \mathrm{O}$ in $1.1 \mathrm{~mL}$ of methanol. In the first solution, UV-Vis was measured without any further treatment. Each of the four solutions were used to characterize two consecutive redox cycles: (i) original Co(II)/TP1 complex, (ii) formation of Co(III)/TP1 complex by oxidation with bromine for $3 \mathrm{~min}$, (iii) reduction to yield back the Co(II)/TP1 complex by adding 40 $\mathrm{mg}$ of ascorbic acid and (iv) second oxidation to synthesize $\mathrm{Co}(\mathrm{III}) / \mathrm{TP} 1$.

\section{Synthesis of functionalized APCNs}

Three different weight ratios (50/50,60/40, and 70/30 wt-\%, written as 50/50,60/40, and 70/30 in the text) of TMS-HEA to PDMS-DMA were used to produce membranes. If not stated otherwise, 60/40 membranes were used. The thickness of the membrane was adjusted by the number of tesa film stripes which were piled on each other as spacers. Each stripe was about $50 \mu \mathrm{m}$ thick (e.g. for a spacer built of four layers tape, membranes with a thickness of $200 \mu \mathrm{m}$ were produced). In total, $0.625 \mathrm{~g}$ of monomer and cross-linker mixture was used per membrane. After premixing of TMS-HEA with TP1 (from $1.25 \mathrm{mg}, 0.0031 \mathrm{mmol}$ to $20 \mathrm{mg}, 0.050 \mathrm{mmol})$ and/or SP (6.25 $\mathrm{mg}, 0.013 \mathrm{mmol}$ ), Irgacure 819 (5 mg, $0.01 \mathrm{mmol}$ ) were added under red light and the mixture was shaken vigorously for 3 min. Thereafter, the corresponding amount of PDMS-DMA was added and the mixture shaken again for $1 \mathrm{~min}$ (Scheme 3 ).

The formulations were inserted as liquid precursos between two glass slides and irradiated for $20 \mathrm{~min}$ with white light $(500$ W lamp). Subsequently, the slides were placed into a mixture of THF and water (50/50 vol-\%) in order to minimize the adhesion between the synthesized APCNs and the glass slides. After $12 \mathrm{~h}$, the membrane was removed and stored in distilled water to avoid the complete drying of the membrane.

\section{Complexation/de-complexation studies}

To ensure the maximum chelation of available terpyridine sites in the membranes with the metal ions (i.e. $\mathrm{Co}(\mathrm{II}), \mathrm{Fe}(\mathrm{II})$ ), the APCNs were immersed in an aqueous solution of $10 \mathrm{~g} / \mathrm{L}$ $\mathrm{FeCl}_{2} .4 \mathrm{H}_{2} \mathrm{O}$ or $\mathrm{CoCl}_{2} .4 \mathrm{H}_{2} \mathrm{O}$ for 2 days, unless stated otherwise.

Subsequently, the membranes were rinsed thoroughly with water to remove excess metal ions. De-complexation was performed by immersing the APCNs in an aqueous solution of 40 wt.-\% HEEDTA for $5 \mathrm{~h}$.

Six membranes were immersed for $1 \mathrm{~min}$ in six different solutions of iron and cobalt chloride at concentrations of $1 \mathrm{~g} / \mathrm{l}$, $5 \mathrm{~g} / \mathrm{l}$ and $10 \mathrm{~g} / \mathrm{l}$.

After drying in a desiccator over molecular sieves for $18 \mathrm{~h}$, their UV-Vis spectra were recorded. The experiment was repeated with the same membranes after total complexation times of $10 \mathrm{~min}, 30 \mathrm{~min}, 1 \mathrm{~h}, 2 \mathrm{~h}, 4 \mathrm{~h}, 8 \mathrm{~h}, 12 \mathrm{~h}, 16 \mathrm{~h}, 24 \mathrm{~h}, 32 \mathrm{~h}$ and $48 \mathrm{~h}$.

\section{Oxido-reduction cycles of $\mathrm{Co}(\mathrm{II}) / \mathrm{Co}$ (III) terpyridyl complex}

Co(II) complexed APCNs were oxidized to Co(III) complex in an aqueous solution of 30 vol-\% hydrogen peroxide for $2 \mathrm{~h}$ (in case only the monomer solution was tested, $\mathrm{H}_{2} \mathrm{O}_{2}$ was not strong enough for oxidation, thus bromine vapour was employed $^{42}$ ) followed by rinsing the APCNs with water. To reduce the $\mathrm{Co}(\mathrm{III})$ to $\mathrm{Co}(\mathrm{II})$ in the second cycle, a $100 \mathrm{~g} / \mathrm{L}$ solution of ascorbic acid in water was applied for $1 \mathrm{~h}$.

\section{Characterization}

Solid-state UV measurements of complexation kinetics were performed using a Lambda 9 spectrometer (Perkin Elmer) in transmission mode.

Peak Force Quantitative Mechanical Property Mapping at the Nanoscale (Peak Force QNM) were performed on a Bruker Icon Atomic Force Microscope (AFM) using silicon Nanoscience Aspire CFMR cantilevers with a force constant of $3 \mathrm{~N} \mathrm{~m}^{-1}$, and a resonant frequency of $75 \mathrm{kHz}$. The radius of a new tip was \pm 8 $\mathrm{nm}$. The set point of the Peak Force applied during the measurements was $1 \mathrm{nN}$, the Peak Force frequency was $2 \mathrm{kHz}$. The cantilever was calibrated on a Bruker PDMS-SOFT-2-12M test sample (nominal elastic modulus was $3.5 \mathrm{MPa}$ ). The scanning speed was $250 \mathrm{~nm} \mathrm{~s}^{-1}$. All AFM measurements were performed at $25{ }^{\circ} \mathrm{C}$ and approx. $30 \%$ humidity of the ambient air.

In order to calculate the membrane swelling, all dimensions were callipered with a Mitutoyo 522 Diamond Master Vernier. A membrane was dried in the desiccator over $4 \AA$ molecular sieves for one day. Afterwards, its volume $\left(V_{0}\right)$ was determined by measuring the side lengths and the thickness. Then the membrane was placed into water or hexane for $24 \mathrm{~h}$ and the volume $\left(V_{1}\right)$ was measured again. For measuring the impact of the merocyanine state on the swelling behavior, a membrane was illuminated with UV-light $\left(366 \mathrm{~nm}, 8 \mathrm{~mW} \mathrm{~cm}^{-2}\right.$ ) during the entire measurement. Each measurement was repeated three times. The volumetric degree of swelling $S$ was calculated using the following formula: 
$S=V_{1} / V_{0}$

The water contact angles of the membranes were determined with a Krüss Contact angle DSA25 device. The membranes were previously dried in a desiccator over molecular sieves for $18 \mathrm{~h}$.

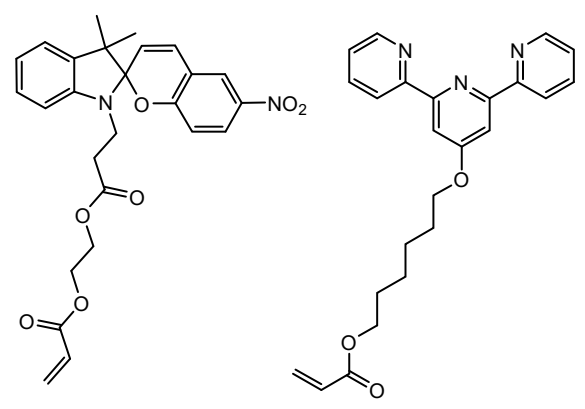

SP
TP1

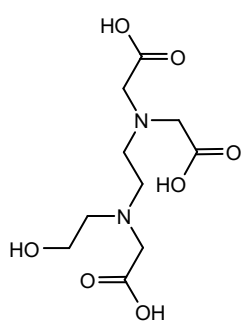

HEEDTA
Scheme 2. Structures of the SP and TP1 monomers employed in the preparation of multi-stimuli-responsive APCNs and the employed de-complexing agent (HEEDTA)

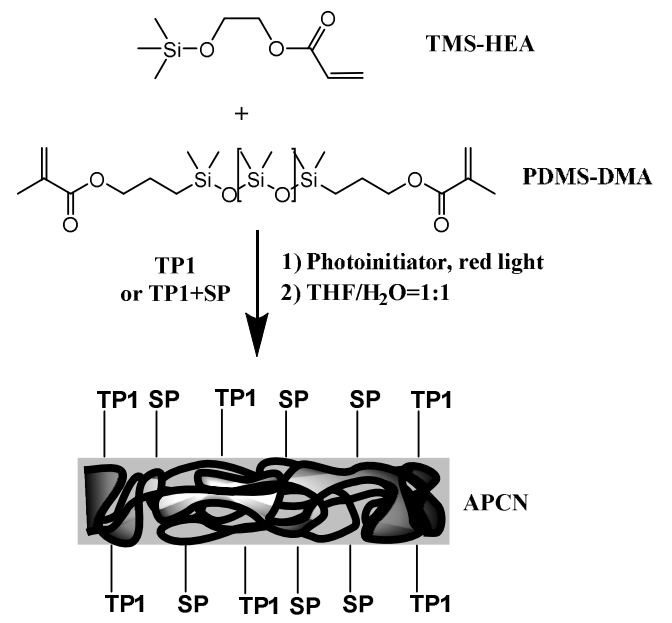

Scheme 3. Synthesis of APCNs functionalized with TP1 and SP.

The value given is an average over 10 measurements at different spots per sample.

All permeability measurements were performed in a Franz diffusion-cell (SES Analysis system, receptor volume $12.0 \mathrm{~mL}$ and orifice area $1.77 \mathrm{~cm}^{2}$ ). Before placing the membranes in the Franz cell, they were either irradiated with UV light (366 $\mathrm{nm}, 8 \mathrm{~mW} . \mathrm{cm}^{-2}$ ) or white light (400-700 nm, 500 Lumen) for 1 $\mathrm{min}$. Mass transfer rates of caffeine were measured under UV irradiation ( $366 \mathrm{~nm}, 8 \mathrm{~mW} . \mathrm{cm}^{-2}$ ) and at daylight. After filling the receptor chamber with water, the membrane was fixed in the diffusion cell. The donor chamber was charged with a caffeine solution $(93 \mathrm{mM}, 3.0 \mathrm{~mL}$ ). Samples $(200 \mu \mathrm{L})$ were collected from the receptor part of the cell, typically after 1 , 15, 30, $45 \mathrm{~min}$ and 1, 1.5, 2, 2.5, 3, 4, 5, 6, 7, 8, 9, 10, 11, $12 \mathrm{~h}$. The caffeine concentrations in these aliquots were determined by measuring its UV absorptions at $293 \mathrm{~nm}$ (calibration curve: $c_{a f f}=(0.9068 * x+0.0212) \mathrm{mmol} / \mathrm{L}, \mathrm{x}:$ measured absorption). The permeability of a membrane at a given caffeine concentration is proportional to the molecular flux $F$ of aqueous caffeine through the membrane, calculated according to

$$
F=n /(A \cdot t)
$$

where $\mathrm{n}(\mathrm{g})$ represents the amount of material that diffuses through a membrane, $A\left(\mathrm{~cm}^{2}\right)$ is the examined section per time $t(s)$. All membranes were stored in water to pre-condition the membranes prior to the permeability measurements.

Electrochemical data was obtained on a $\mathrm{CH}$ Instruments $900 \mathrm{~B}$ potentiostat using platinum mesh and silver wire as the counter and reference electrodes; membrane coated FTO, or a Pt disk electrode were used as the working electrodes for the membrane and solution samples respectively. In the case of the membrane samples, ITO coated glass slides from SigmaAldrich (resistivity 8-12 $\Omega / \mathrm{sq}$ ) were functionalized with acrylated silane. The substrates were cleaned in an argon/oxygen (gas flow 16:4 sccm) plasma chamber at $80 \mathrm{~W}$ for $15 \mathrm{~min}$ under vacuum (self-built asymmetric reactor chamber with a circular gas showerhead powered by a Dressler). Surfaces were then immersed for $2 \mathrm{~h}$ under argon flow at room temperature into a solution of $20 \% 3$ methacryloypropyl trimethoxysilane in dry toluene. After modification, ITO electrodes were rinsed with toluene and water before being dried in a desiccator over molecular sieves. TP1 and iron(II) chloride were added together in a ratio of 2:1 (ligand/metal) in methanol $(10 \mathrm{~mL})$ and after one hour the solution was treated with excess ammonium hexafluorophosphate and water $(3 \mathrm{~mL})$ to precipitate $\left[\mathrm{Fe}(\mathrm{TP} 1)_{2}\right]\left[\mathrm{PF}_{6}\right]_{2}$. The suspension was filtered over Celite and washed with cold methanol ( $83 \%$ yield).

All samples were run in HPLC grade acetonitrile containing 0.1 $\mathrm{M}\left[{ }^{\mathrm{n}} \mathrm{Bu}_{4} \mathrm{~N}\right]\left[\mathrm{PF}_{6}\right]$ as the supporting electrolyte at a scan rate of $0.1 \mathrm{~V} \mathrm{~s}^{-1}$; all solutions were degassed with argon. Cyclic voltammetry was performed on homoleptic iron(II) complexes (c.a $10^{-4} \mathrm{~mol} \mathrm{dm}^{-3}$ ) and on membranes fixed to indium tin oxide (ITO) coated glass slides. $\mathrm{Cp}_{2} \mathrm{Fe}$ was added to the electrolyte after each set of scans and run as anternal reference.

\section{Results and discussion}

Redox behaviour of TP1 monomer in the presence of $\mathrm{Co}$ (II)/Co(III) or $\mathrm{Fe}(\mathrm{II}) / \mathrm{Fe}$ (III) redox pairs

Compound TP1 behaves as typical tpy ligand and forms 2:1 complexes with transition metal ions such as iron(II) or cobalt (II) in methanol ${ }^{39,40,42}$. The complex formation leads to intensely purple $\left(\mathrm{Fe}^{2+}\right)$ or orange $\left(\mathrm{Co}^{2+}\right)$ coloured solutions. The homopletic complexs $\left[\mathrm{M}^{2+}(\mathrm{TP} 1)_{2}\right]\left[\mathrm{PF}_{6}\right]_{2}$ were isolated as purple $\left(\mathrm{Fe}^{2+}\right)$ and orange $\left(\mathrm{Co}^{2+}\right)$ solids. The presence of the paramagnetic cobalt(II) ion bound to the TP1 ligand was confirmed by ${ }^{1} \mathrm{H}$ NMR experiments where unusually strongly 
de-shielded resonances are characteristic of $\left[\mathrm{Co}(\mathrm{tpy})_{2}\right]^{2+}$ complexes (Figure S-1). After oxidation with bromine vapor, all 1

H NMR resonances were observable in their "normal" chemical shift region, confirming the formation of the diamagnetic $\mathrm{Co}$ (III) complex (Figure S-3b and S-3c) ${ }^{42}$.

The reversibility of the oxidation/reduction reactions of the $\mathrm{Co}(\mathrm{II}) / \mathrm{Co}$ (III) couple in the presence of TP1 ligand is shown by two redox cycles in Fig. 1. The paramagnetic Co(II) shows a pronounced UV absorption at $400-500 \mathrm{~nm}$ which is not present in the yellow $\mathrm{Co}$ (III) complex (diamagnetic).

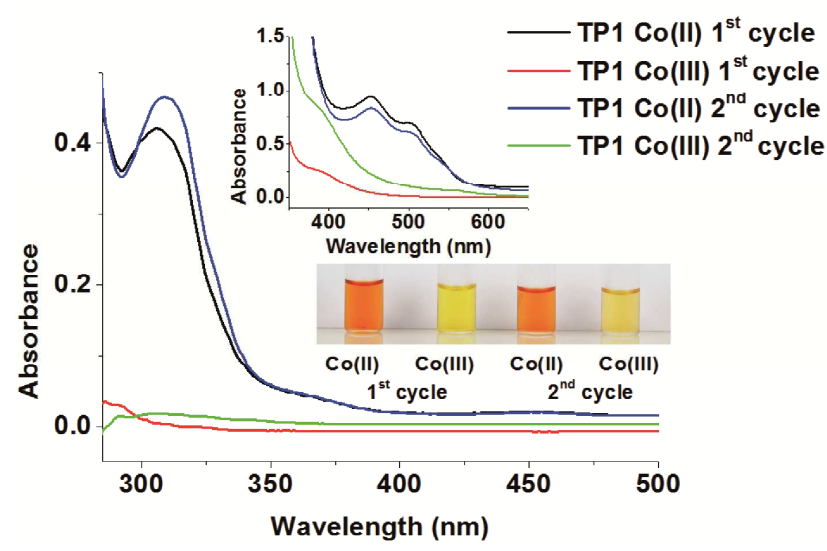

Figure 1. Optical changes recorded by UV-Vis in $\mathrm{CH}_{3} \mathrm{OH}$ during two consecutive redox cycles of TP1 (0.1 wt.-\%) and $\mathrm{Co}(\mathrm{II}) / \mathrm{Co}(\mathrm{III})$ complex $\left(\left[\mathrm{CoCl}_{2}\right]=16.8 \mathrm{mM}\right)$. Bromine vapour was used as oxidant whereas ascorbic acid $(0.1 \mathrm{M})$ was the reducing agent. In the inset double concentrations of $\mathrm{CoCl}_{2}$ and TP1 were employed.

Oxidations were performed by bromine vapour and reductions with ascorbic acid.

A slight change in the optical properties after the first redox cycle may be due to the acidity of the ascorbic acid employed in the $\mathrm{Co}(\mathrm{III}) / \mathrm{Co}(\mathrm{II})$ reduction which affects the dispersion/aggregation of tpy units in solution. It is worth mentioning that the redox switching occurs with relatively mild and biocompatible oxidising and reducing agents. Previous studies have already shown low switching potential (i.e. -0.30 V vs. SCE for 2,2'-bipyridine with $\mathrm{Co}(\mathrm{II}) / \mathrm{Co}(\mathrm{III})$ ) and versatility in the choice of oxidizing and reducing agents when cobalt(II)-tpy complexes are deployed ${ }^{43,44}$. This feature is extremely useful for drug delivery applications, where the main target is to vary the permeability of the membrane without any chemical modification of the loaded drug.

\section{Characterization and redox switch behaviour of APCNs modified with TP1 in the presence of $\mathrm{Co}$ (II)/Co(III) or Fe(II)/Fe(III) redox pairs}

Mechanically stable films of amphiphilic polymer co-networks were synthesized for use as membranes. Amphiphilic poly(2hydroxyethyl acrylate)-co-poly(dimethylsiloxane) (PHEA-coPDMS) co-networks were chosen as substrate due to their inherent mechanical stability, functionalization versatility, the wide composition range in which the nanophase separation occurs and straightforward synthesis. ${ }^{19,45-48}$ Such networks are synthesized via white-light initiated radical copolymerization of $\alpha, \omega$-dimethacryloxypropyl-terminated PDMS with the hydrophobic trimethylsilated HEA to prevent macrophase separation prior to polymerization ${ }^{19}$. The silyl protecting groups are then removed using a THF/ $\mathrm{H}_{2} \mathrm{O}$ 50/50 vol-\% solution to transform the TMS-protected acrylate co-network segments into the respective hydrophilic PHEA segments. This de-protection step was followed via the appearance of a band in the IR spectrum at $3400 \mathrm{~cm}^{-1}$ corresponding to the free $-\mathrm{OH}$ group.

Co-polymerizations with TP1 and/or SP monomers were achieved by thoroughly mixing together with HEA prior to initiating the reaction (Scheme 3). We determined via absorbance calibration at $556 \mathrm{~nm}$ after complexation with $\mathrm{Fe}(\mathrm{II})$ that about $94 \%$ of the total mass of TP1 added to the solution was co-polymerized in the membrane (Fig. S-4). The analysis of the membrane by XPS confirmed the presence of terpyridine with a weak peak corresponding to $0.46 \%$ of $\mathrm{N} 1 \mathrm{~s}$ in the organic matrix (400 eV) (Table S-1).

The inclusion of tpy metal-binding domains in the APCNs cause a slight increase of the overall swelling of the matrix in nhexane and an opposite trend with swelling in water, probably due to the higher hydrophobicity of the membrane once the hydroxyl groups are replaced by tpy domains (Figure S-6B). As a result, also the contact angle values increases from $82^{\circ}$ up to $105^{\circ}$ once the amphiphilic co-network is functionalized with 0.4 wt.-\% of TP1 (Figure S-8b).

Inclusion of TP1 in the polymer network (i.e. $0.4 \mathrm{wt} .-\%$ ) did not alter the overall behaviour of the APCN membrane, as at increasing PHEA/PDMS ratios (i.e. by increasing the hydrophilic phase), the swelling in water slightly increase whereas the opposite trend is observed for swelling in hexane (Figure S-5).

This feature has already been observed in previous pristine APCNs membrane ${ }^{19,45}$ Both swellings are independent but are rather low compared to hydrogels because the two covalently linked phases restricted each other. Therefore, the incorporation of tpy does not affect the inherent properties of APCNs.

The TP1 functionalization degree did not affect the overall swelling of the matrix, although the permeability values of the modified APCN membrane at increasing content of TP1 from 0 to $3.2 \mathrm{wt}-\%$ shows a minimum with $0.4 \mathrm{wt}$.\% TP1 (Figure S-6a). This effect might be the result of two different phenomena: on one side, at lower TP1 content, hydrophobic interactions between the tpy domains might become prevalent and the consequent increase in the network interactions could contribute to a reduction of the nanochannels size and in the permeability. On the other hand, the increase of free volume occurring by weaker binding between the acrylic phases contributes to an increase in permeability.

The formation of metal cross-linking occurring between the tpy moieties present in the functionalized APCNs was tested by the addition of $\mathrm{CoCl}_{2}$ and $\mathrm{FeCl}_{2}$ (complexation studies of the single TP1 monomer can be found in the Supplementary Information).

The complexation of $\mathrm{Co}^{2+}$ to polymer-bound TP1 sites was studied by the UV-Vis absorbance at $455 \mathrm{~nm}$ as function of the 
TP1 concentration (Fig. 2A). We found a continuous increase of the absorbance between 0.2 and 3.2 wt-\% of TP1 in the presence of sufficient amounts of cobalt, whereas the reference spectrum of $\mathrm{CoCl}_{2}$ solutions showed no absorbance at this wavelength. Furthermore, we followed the kinetics of iron(II) to polymer bound TP1 by monitoring the strong absorbance at $559 \mathrm{~nm}^{40}$ (Fig. 2B). We observe no further increase of the intensity of this band after 8 hours indicating that all present TP1 sites were fully complexed with iron.
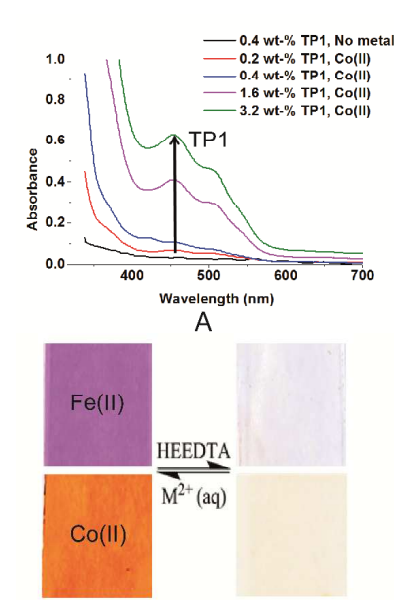

C

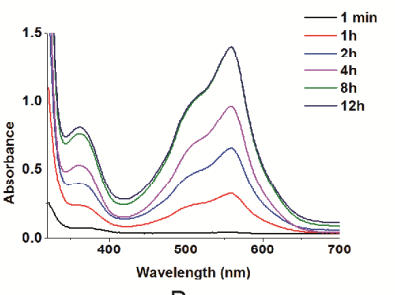

B

Figure 2. UV-Vis spectra of membranes with different TP1 contents (0.2-3.2 wt.-\%) after two days reaction with $10 \mathrm{~g} / \mathrm{L} \mathrm{CoCl}_{2}(\mathrm{~A})$ and complexation kinetics of 0.4 wt.-\% TP1 functionalized APCNs monitored by UV-Vis measurements at a concentration of 5 $\mathrm{g} / \mathrm{L}$ iron(II) chloride in aqueous solutions (B). Change of colour of the APCN membranes is associated with both $\mathrm{Co}(\mathrm{II}) / \mathrm{Co}(\mathrm{III})$ and $\mathrm{Fe}(\mathrm{II}) / \mathrm{Fe}$ (III) systems when complexation occurs (B).

In the case of a methacrylate polymer functionalized with tpy units, it has previously been shown that the complexation kinetics of $\mathrm{Cu}(\mathrm{II})$ ions, observed as an increase in solution viscosity, went to completion within a period of two days ${ }^{49}$. In our case, the complexation reaction reached equilibrium after $8 \mathrm{hrs}$. The faster kinetic of our Fe(II)-tpy system might be related to the overall higher surface area (i.e. presence of nanochannels) of APCN compared to the previously studied methacrylate polymer.

It is important to notice how the supramolecular cross-linking density, in turn related to the swelling and permeability, can be tuned by the functionalization degree of terpyridine in the membrane, the concentration of metal ion in solution and the complexation time.

The complexation between tpy and iron (II) was previously demonstrated to be reversible upon addition of the hydroxyethyl(ethylenediaminetriacetic acid) (HEEDTA), a competing metal chelator. ${ }^{35,50,51}$ In this study, the reversible complexation/decomplexation of the membranes with cobalt(II) and iron(II) was observed by the colour switch upon treatment with HEEDTA (Figure 2C). We expected two opposite structural responses of the membrane upon complexation with a metal. The first one is an increase in the swelling capacity due to increasing number of ionic groups in hydrogel. ${ }^{52}$ The second mechanism is an intermolecular crosslinking of the PHEA phase. ${ }^{43,53}$ We determined the degree of crosslinking of membranes with 0.4 wt-\% of TP1 without metal and after complexation in cobalt chloride, by PeakForce QNM images (Figure 3). Peak force atomic force microscopy (AFM) height maps and DMT modulus maps of the amphiphilic co-network shows, in the absence of any complexation, a nanophase separation even when PHEA is functionalized with TP1 (Figure 3).

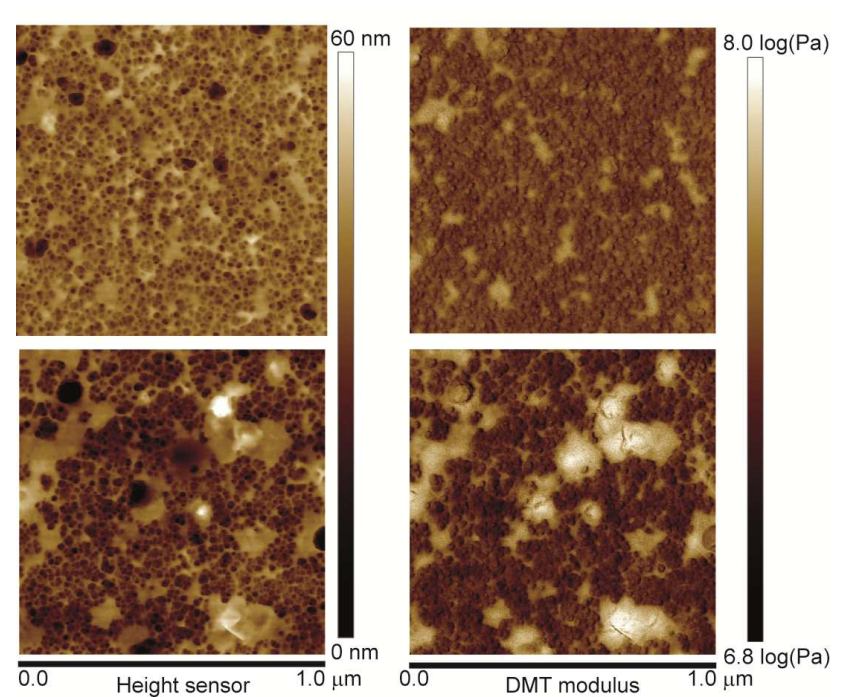

Figure 3. Variation of height sensor (left) and DMT modulus (right) of TP1 (0.4 wt.-\%) functionalized APCNs as measured by AFM before (top) and after (bottom) exposure to $10 \mathrm{~g} / \mathrm{L} \mathrm{CoCl}_{2}$.

The bright phase is assumed to be PHEA whereas the dark phase is assumed to correlate with PDMS ${ }^{19,45}$. It is important to notice how the height maps and the DMT modulus maps show specular profiles. Therefore, this difference between the two phases at constant force might be a consequence of the lower Young's modulus for the PHEA phase.

Upon complexation with cobalt(II) chloride, the nanophase structures collapse to form phase aggregates as a result of the cross-linking occurring in the PHEA phase. This aggregation is registered also by mapping the DMT modulus of the network (right in Figure 3), where an increased stiffness of the membrane caused by a tighter network induce an increase in the DMT modulus mainly in the PHEA phase. As our previous study has already shown ${ }^{19}$, also adhesion maps confirm the interconnected structure of the PHEA domains, obtaining higher values of adhesion for the PHEA phase as compared to the PDMS phase.

\section{Influence of redox cycles on optical, morphological and permeability properties of APCNs}

In the first section, we have shown the fully reversible redox switching between $\mathrm{Co}(\mathrm{II})$ and $\mathrm{Co}(\mathrm{III})$ in the presence of the TP1 monomer (Figure 1). Once TP1 is covalently functionalized in 
the APCN membrane, a similar switch would result in two different permeability states. This is indeed observed by performing two redox cycles for the TP1 functionalized conetwork (Figure 4). Oxidation occurred after submerging the membrane in a hydrogen peroxide solution. It is reflected by a change in colour to yellow, a decrease of the absorbance at $455 \mathrm{~nm}$ and an increase in the permeability.

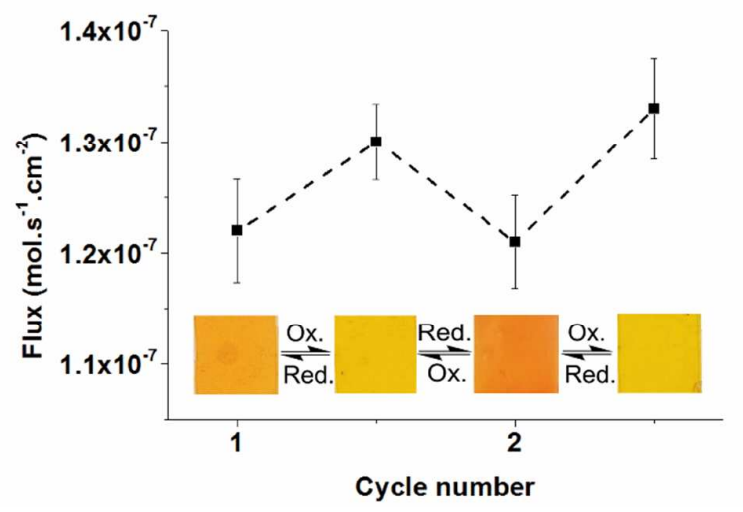

Figure 4. Reversibility of redox response: Permeability of Co(II) loaded membranes containing 1.6wt.-\% TP1. The flux is calculated based on the slope of the absorbance of caffeine as a function of time (Franz diffusion cell).

The increase in permeability upon oxidation from $\mathrm{Co}(\mathrm{II})$ to $\mathrm{Co}$ (III) of the redox responsive membrane is about $10 \%$ and the illustrated two redox cycles show a substantial repeatability (within the standard deviation error) of the two different permeability states.

The effect on the permeability is associated with an $8 \%$ increase in the swelling in water in the presence of the higher oxidation state of metal ion due to an increase in the overall polarity of the network (Figure S-9). The reversibility of the membrane redox responsive properties are demonstrated by a return to the original cobalt(II) state upon chemical reduction with ascorbic acid.

In order to study the Fe/TP1 monomer electrochemical response, an iron(II) homoleptic complex $\left[\mathrm{Fe}(\mathrm{TP} 1)_{2}\right]^{2+}$ was prepared and measured by solution phase electrochemistry in acetonitrile (Figure 5A) The cyclic voltammogram showed, one reversible metal-centered oxidation at $E_{1 / 2}=+0.59 \mathrm{~V}$, two reversible ligand-centred reductions at $E_{1 / 2}=-1.74$ and $-1.92 \mathrm{~V}$ (vs $\mathrm{Fc} / \mathrm{Fc}^{+}$) corresponding to TP1/TP1 and $\mathrm{TP} 1^{-} / \mathrm{TP} 1^{2-}$ redox couples, and some irreversible reductions at higher negative potentials $(-2.40 \mathrm{~V})$ that were assumed to be TP1 $1^{2-} / \mathrm{TP} 1^{3-}$ and reductions on the alkene groups ${ }^{54,55}$.

The values for the isolated complex $\left[\mathrm{Fe}(\mathrm{TP} 1)_{2}\right]\left[\mathrm{PF}_{6}\right]_{2}$ were then compared with the cyclic voltammogram obtained from an iron complexed membrane with 1.6 wt-\% of TP1 coated on ITO-coated glass slides (Figure 5B). The results showed a reversible oxidation at $E_{1 / 2}=+0.66 \mathrm{~V}$ after stabilization of the system. If compared with the metal-centered oxidation of the iron complex of the TP1 monomer, the $E_{1 / 2}$ shows similar values as expected.
Thus it can be stated that the inclusion of TP1 in the membrane does not affect the redox behavior of the $\mathrm{Fe}(\mathrm{II}) / \mathrm{Fe}(\mathrm{III})$ transition.

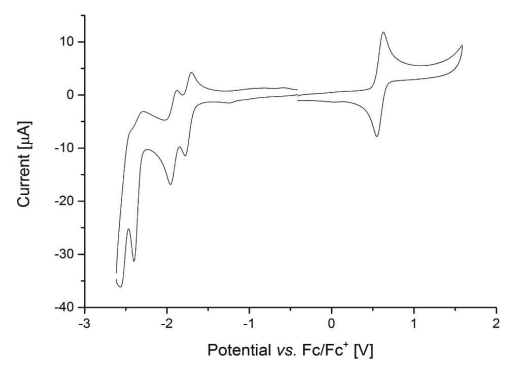

A

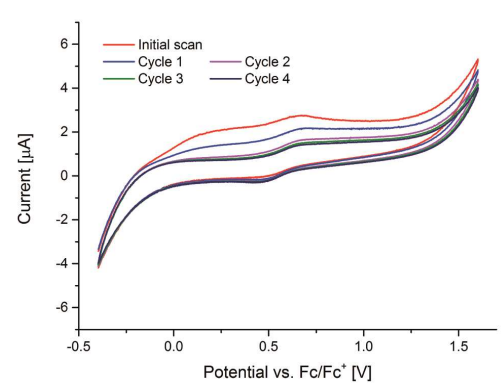

B

Figure 5. Cyclic voltammogramms of homoleptic iron complex of TP1 (A) and APCN membranes functionalized with 1.6 wt.-\% TP1, complexed with $\mathrm{FeCl}_{2}$ and coated on double layer ITO/glass (B); MeCN solns containing $0.1 \mathrm{M}\left[{ }^{\mathrm{n}} \mathrm{Bu}_{4} \mathrm{~N}\right]\left[\mathrm{PF}_{6}\right]$ as the supporting electrolyte ( $v s . \mathrm{Fc} / \mathrm{Fc}^{+}$; scan rate $=0.1 \mathrm{~V} \mathrm{~s}^{-1}$ )

\section{Influence of redox and light switches on permeability, swelling and surface properties of APCNs}

The light-responsive properties of SP-functionalized APCNs were previously characterized by UV-Vis and permeability measurements ${ }^{19}$. Under UV light, the isomerization from SP to the merocyanine (MC) zwitteronic form with an extended conjugated $\pi$-electron system resulted in an increase of up to $50 \%$ of the permeability and the development of a strong absorption band around $545 \mathrm{~nm}$. This significant change in permeability due to an increase in polarity proved beneficial for implementing a membrane gating or drug delivery system. $^{19,22}$

The switch in optical absorbance of APCNs membranes functionalized with 0.4 wt-\% TP1 and 1.0 wt.-\% SP units was tested in the de-complexed state and when $\mathrm{Fe}$ (II) and $\mathrm{Co}$ (II) were incorporated in the network (Figure S-7). This study has been performed to understand whether the inclusion of TP1 in the network affects the SP/MC light switch.

The effect of UV light on all the absorption spectra was characterized by the development of an intense band at a wavelength of about $545 \mathrm{~nm}$. The intensity of the band at $545 \mathrm{~nm}$ determined from the difference between the absorbance after $1 \mathrm{~min}$ white light and the one after $1 \mathrm{~min}$ UV 
light quantifies the influence of the metal on the merocyanine UV-Vis spectrum. Although a slight hypsochromic shift was observed due to change in the polarity and in the degree of flexibility of the SP inside the membrane, the spiropyranmerocyanine isomerization occurs in all samples tested.

Although the functionalization of APCNs with TP1 has shown a $30 \%$ increase in the contact angle, SP-modified membranes did not reveal any significant differences compared to the pristine ones (Figure S-8). Once both SP and TP1 are present in the co-network, swelling and contact angle values are within the range observed in the presence of a single switching functionality.

In addition, an increase in water swelling as well as a decrease in contact angle and hexane swelling was observed on moving from the de-complexed to the complexed stage for SP and TP1 functionalized membranes (Figure S-9). This is probably induced by the overall increase in the network polarity as a consequence of the metal ion inclusion.

A higher difference in flux was observed between decomplexed stage and the cobalt(II) treated material under UV light ( $6 \%$ under white light and $16 \%$ under UV light). No change in contact angle occurred, suggesting that structural rearrangements occur in the bulk or within one phase of the APCN.

By comparing the effect of UV light with and without cobalt, it is clear that the increase in polarity is much higher in the presence of the metal ion, especially with $\mathrm{Co}(\mathrm{III})$. This change is reflected in a slight increase in the swelling degree in water, a noticeable difference in contact angle and a larger difference in permeability between UV and white light. Such divergence in permeability might be explained by stabilization of the merocyanine form which causes a shift in the spiropyran/merocyanine (MC) equilibrium. ${ }^{56,57}$

Hence, membranes containing both TP1 and SP ligands, show that the light, metal and redox state, have synergic effects on the UV-Vis spectrum and permeability.

The reversibility of the isomerization from SP to the MC form in a membrane with $0.4 \mathrm{wt}-\%$ TP1 and $1 \mathrm{wt} .-\%$ SP complexed to $\mathrm{Co}(\mathrm{II})$ was evidenced by a change in colour and the increase in absorption peak of the merocyanine form at $544 \mathrm{~nm}$ (Fig.6A).

The synergic effect of the redox $\mathrm{Co}(\mathrm{II}) / \mathrm{Co}$ (III) couple and the light switch spyropiran/merocyanine showed four different possible states of permeability rates for the SP and TP1 APCNs membrane (Figure 6B). The difference in permeability between open and closed forms of SP is constant at $45 \%$ in the presence of $\mathrm{Co}(\mathrm{II})$ or $\mathrm{Co}(\mathrm{III})$, whereas an overall increase of 96 $\%$ in permeability can be observed from State 1 (white light, no metal) to State 6 (UV light, Co(III)). The encapsulation of a light switch in the redox-responsive membrane tremendously increases the permeability range in which the dual-responsive system is able to operate. Previously synthesized spyropyranmodified APCNs have shown only a $50 \%$ variation between the SP-APCN and MC-APCN forms ${ }^{19}$. The enhanced control in permeability and the highest range achievable with this matrix allows a finer tuning of the pharmacokinetic effect for drugdelivery applications.
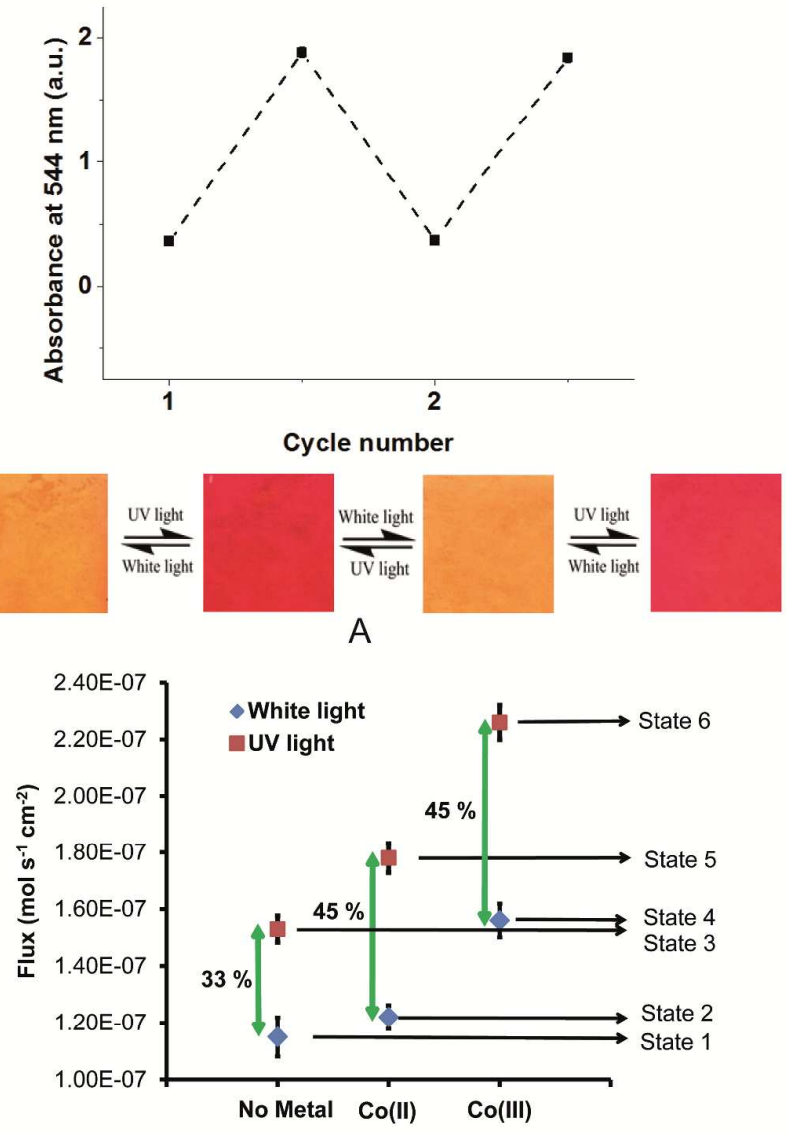

B

Figure 6. Reversibility of the white light/UV light switch shown by UV-Vis spectroscopy for 0.4 wt.-\% TP1 and 1 wt.-\% SP functionalized APCNs after complexation with $10 \mathrm{~g} / \mathrm{L}$ of $\mathrm{CoCl}_{2}$ for $48 \mathrm{hrs}$ (aq) (A); four different states of permeabilities for $0.4 \mathrm{wt.}$. $\%$ TP1 and 1 wt.-\% SP functionalized APCNs in the presence of light and redox switches (B).

\section{Conclusions}

In conclusion, we have prepared mechanically-stable multi stimuli-responsive membranes by copolymerizing acrylateterminated spiropyran and tpy monomers with TMS-protected 2-hydroxyethylacrylate and a methacrylate-terminated poly(dimethylsiloxane) cross-linker. After light-induced copolymerization and deprotection, the system exhibits a nanophase separated amphiphilic conetwork structure with variable morphology and hydrophobicity depending on the terpyridine, spiropyran, PHEA and PDMS contents. Complexation of tpy with cobalt(II) or iron(II) in aqueous solution led to a material with a tunable degree of crosslinking. Furthermore, by incorporating these metal ions in the membranes, metal complexes addressable to external stimuli were formed. As a result, we demonstrated the changes in permeability, optical and morphological properties as a response to complexation/de-complexation, redox conditions and light. Furthermore, all combinations of responsive 
environment, i.e. metal ions/HEEDTA (competitive ligand), oxidative/reductive agents and UV/white light, were shown to induce reversible changes in their optical properties. It was demonstrated that the combination of different stimuliresponsive monomers not only lead to an extension of the single responsive functionalities towards multi-responses, but also to a synergistically increased response in permeability upon two or more stimuli. These metal ion-, redox- and lightresponsive membranes showing multiple reversible property variations are thus exceptionally promising for their use in drug-delivery applications.

\section{Acknowledgements}

Katrin Schöller is grateful for a Marie Curie postdoctoral fellowship (FP7) from 2012-2014. The authors gratefully acknowledge the support of Max Aeberhard, Lea Oberhänsli, Karl Kehl and Patrick Rupper.

\section{Notes and references} G. Erdodi and J. P. Kennedy, Prog. Polym. Sci., 2006, 31, 118.

2 C.-W. Wang, C. Liu, X.-W. Zhu, Z.-Y. Yang, H.-F. Sun, D.-L. Kong and J. Yang, J. Polym. Sci. Part A Polym. Chem., 2016, 54, 407-417.

3 G. Kali, T. K. Georgiou, B. Iván, C. S. Patrickios, E. Loizou, Y. Thomann and J. C. Tiller, Macromolecules, 2007, 40, 21922200.

4 C. Lin and I. Gitsov, Macromolecules, 2010, 43, 1001710030.

5 Y. Sun, J. Maughan, R. Haigh, S. a. Hopkins, P. Wyman, C. Johnson, N. J. Fullwood, J. Ebdon, S. MacNeil and S. Rimmer, Macromol. Symp., 2007, 256, 137-148.

$6 \quad$ N. Bruns and J. C. Tiller, Nano Lett., 2005, 5, 45-48.

7 G. Erdodi and J. P. Kennedy, J. Polym. Sci. Part A Polym. Chem., 2005, 43, 4965-4971.

8 M. Hanko, N. Bruns, S. Rentmeister, J. C. Tiller and J. Heinze, Anal. Chem., 2006, 78, 6376-6383.

9 S. K. Jewrajka, G. Erdodi, J. P. Kennedy, D. Ely, G. Dunphy, S. Boehme and F. Popescu, J. Biomed. Mater. Res. A, 2008, 87, 69-77.

10 J. Kost and R. Langer, Adv. Drug Deliv. Rev., 2012, 64, 327341.

11 S. Mura, J. Nicolas and P. Couvreur, Nat. Mater., 2013, 12, 991-1003.

12 A. Chan, R. P. Orme, R. a. Fricker and P. Roach, Adv. Drug Deliv. Rev., 2013, 65, 497-514.

13 R. Cheng, F. Meng, C. Deng, H.-A. Klok and Z. Zhong, Biomaterials, 2013, 34, 3647-3657.

14 Y. Zhao, in Smart Light-Responsive Materials, John Wiley \& Sons, Inc., 2008, pp. 215-242.

15 S. Menon, R. Thekkayil, S. Varghese and S. Das, J. Polym. Sci. Part A Polym. Chem., 2011, 49, 5063-5073.

16 M. Herder, B. M. Schmidt, L. Grubert, M. Pätzel, J. Schwarz and S. Hecht, J. Am. Chem. Soc., 2015, 137, 2738-2747.
B. Heinz, S. Malkmus, S. Laimgruber, S. Dietrich, C. Schulz, K. Rück-Braun, M. Braun, W. Zinth and P. Gilch, J. Am. Chem. Soc., 2007, 129, 8577-84.

R. Klajn, Chem. Soc. Rev., 2014, 43, 148-184.

K. Schöller, S. Küpfer, L. Baumann, P. M. Hoyer, D. de Courten, R. M. Rossi, A. Vetushka, M. Wolf, N. Bruns and L. J. Scherer, Adv. Funct. Mater., 2014, 24, 5194-5201.

L. Baumann, D. de Courten, M. Wolf, R. M. Rossi and L. J. Scherer, ACS Appl. Mater. Interfaces, 2013, 5, 5894-5897. L. Baumann, K. Schöller, D. de Courten, D. Marti, M. Frenz, M. Wolf, R. M. Rossi and L. J. Scherer, RSC Adv., 2013, 3, 23317-23326.

A. C. Pauly, K. Schöller, L. Baumann, R. M. Rossi, K. Dustmann, U. Ziener, D. de Courten, M. Wolf, L. F. Boesel and L. J. Scherer, Sci. Technol. Adv. Mater., 2015, 16, 1-13. F. Meng, W. E. Hennink and Z. Zhong, Biomaterials, 2009, 30, 2180-2198.

P. Kuppusamy, H. Li, G. Ilangovan, A. J. Cardounel, J. L. Zweier, K. Yamada, M. C. Krishna and J. B. Mitchell, Cancer Res., 2002, 62, 307-312.

E. Lallana and N. Tirelli, Macromol. Chem. Phys., 2013, 214, 143-158.

M. Huo, J. Yuan, L. Tao and Y. Wei, Polym. Chem., 2014, 5, 1519-1528.

A. Ghoh, S. Banerjee and B. Voit, Porous Carbons Hyperbranched Polymers - Polymer Solvation, 2015, vol. 266.

M. Gallei, Macromol. Chem. Phys., 2014, 215, 699-704.

A. K. Miller, Z. Li, K. A. Streletzky, A. M. Jamieson and S. J. Rowan, Polym. Chem., 2012, 3, 3132-3138.

B. Dhara and N. Ballav, RSC Adv., 2013, 3, 4909.

F. Peng, G. Li, X. Liu, S. Wu and Z. Tong, J. Am. Chem. Soc., 2008, 130, 16166-16167.

Z. Sun, F. Lv, L. Cao, L. Liu, Y. Zhang and Z. Lu, Angew. Chemie Int. Ed., 2015, 54, 7944-7948.

M. Tagliazucchi, F. J. Williams and E. J. Calvo, Chem. Commun. (Camb)., 2010, 46, 9004-9006.

A. Kristanti, R. Batchelor, M. Albuszis, J. Yap and P. J. Roth, Eur. Polym. J., 2015, 69, 499-509.

Z. Ge and S. Liu, Macromol. Rapid Commun., 2013, 34, 922-30.

6 J. F. Gohy, B. G. G. Lohmeijer, S. K. Varshney, B. Decamps, E. Leroy, S. Boileau and U. S. Schubert, Macromolecules, 2002, 35, 9748-9755.

M. a R. Meier, B. G. G. Lohmeijer and U. S. Schubert, J. Mass Spectrom., 2003, 38, 510-516.

A. Gasnier, C. Bucher, J.-C. Moutet, G. Royal, E. Saint-Aman and P. Terech, Macromol. Symp., 2011, 304, 87-92.

S. Köytepe, M. H. Demirel, A. Gültek and T. Seçkin, Polym. Int., 2014, 63, 778-787.

U. Mansfeld, A. Winter, M. D. Hager, R. Hoogenboom, W. Günther and U. S. Schubert, Polym. Chem., 2013, 4, 113. S. Bode, L. Zedler, F. H. Schacher, B. Dietzek, M. Schmitt, J. Popp, M. D. Hager and U. S. Schubert, Adv. Mater., 2013, 25, 1634-8.

H. S. Chow, E. C. Constable, C. E. Housecroft, K. J. Kulicke and Y. Tao, Dalt. Trans., 2005, 236-237. 
43 Y. Chujo, K. Sada and T. Saegusa, Macromolecules, 1993, 26, 6320-6323.

44 T. A. Asoh, H. Yoshitake, Y. Takano and A. Kikuchi, Macromol. Chem. Phys., 2013, 214, 2534-2539.

45 N. Bruns, J. Scherble, L. Hartmann, R. Thomann, B. Iván, R. Mülhaupt and J. C. Tiller, Macromolecules, 2005, 38, 24312438.

46 J. C. Tiller, C. Sprich and L. Hartmann, J. Control. Release, 2005, 103, 355-367.

47 M. Hanko, N. Bruns, J. C. Tiller and J. Heinze, Anal. Bioanal. Chem., 2006, 386, 1273-83.

48 S. Dech, T. Cramer, R. Ladisch, N. Bruns and J. C. Tiller, Biomacromolecules, 2011, 12, 1594-1601.

49 K. J. Calzia and G. N. Tew, Macromolecules, 2002, 35, 6090-6093.

50 H. Hofmeier and U. S. Schubert, Macromol. Chem. Phys., 2003, 204, 1391-1397.

51 S. Song, Y. Xue, L. Feng, H. Elbatal, P. Wang, C. N. Moorefiel, G. R. Newkome and L. Dai, Angew. Chemie - Int. Ed., 2014, 53, 1415-1419.

52 O. Okay, in Hydrogel Sensors and Actuators SE - 1, eds. G. Gerlach and K.-F. Arndt, Springer Berlin Heidelberg, 2010, vol. 6, pp. 1-14.

53 S. Bode, R. K. Bose, S. Matthes, M. Ehrhardt, a. Seifert, F. H. Schacher, R. M. Paulus, S. Stumpf, B. Sandmann, J. Vitz, a. Winter, S. Hoeppener, S. J. Garcia, S. Spange, S. van der Zwaag, M. D. Hager and U. S. Schubert, Polym. Chem., 2013, 4, 4966-4973.

54 S. Seo, J. Lee, S.-Y. Choi and H. Lee, J. Mater. Chem., 2012, 22, 1868-1875.

55 H. S. Chow, E. C. Constable, C. E. Housecroft, M. Neuburger and S. Schaffner, Dalton Trans., 2006, 2881-90.

56 J. D. Winkler, C. M. Bowen and V. Michelet, J. Am. Chem. Soc., 1998, 120, 3237-3242.

57 R. J. Byrne, S. E. Stitzel and D. Diamond, J. Mater. Chem., 2006, 16, 1332-1337. 


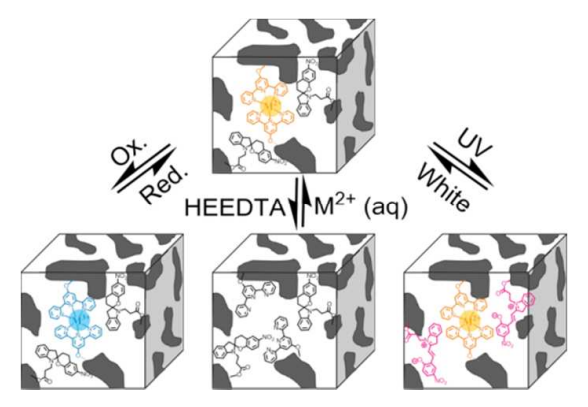

Amphiphilic polymer conetworks were functionalized with spyropiran and terpyridine yielding multiresponsive membranes with switchable properties and potential applications in drug delivery and medical sensors 


\section{Page 17 of 37}

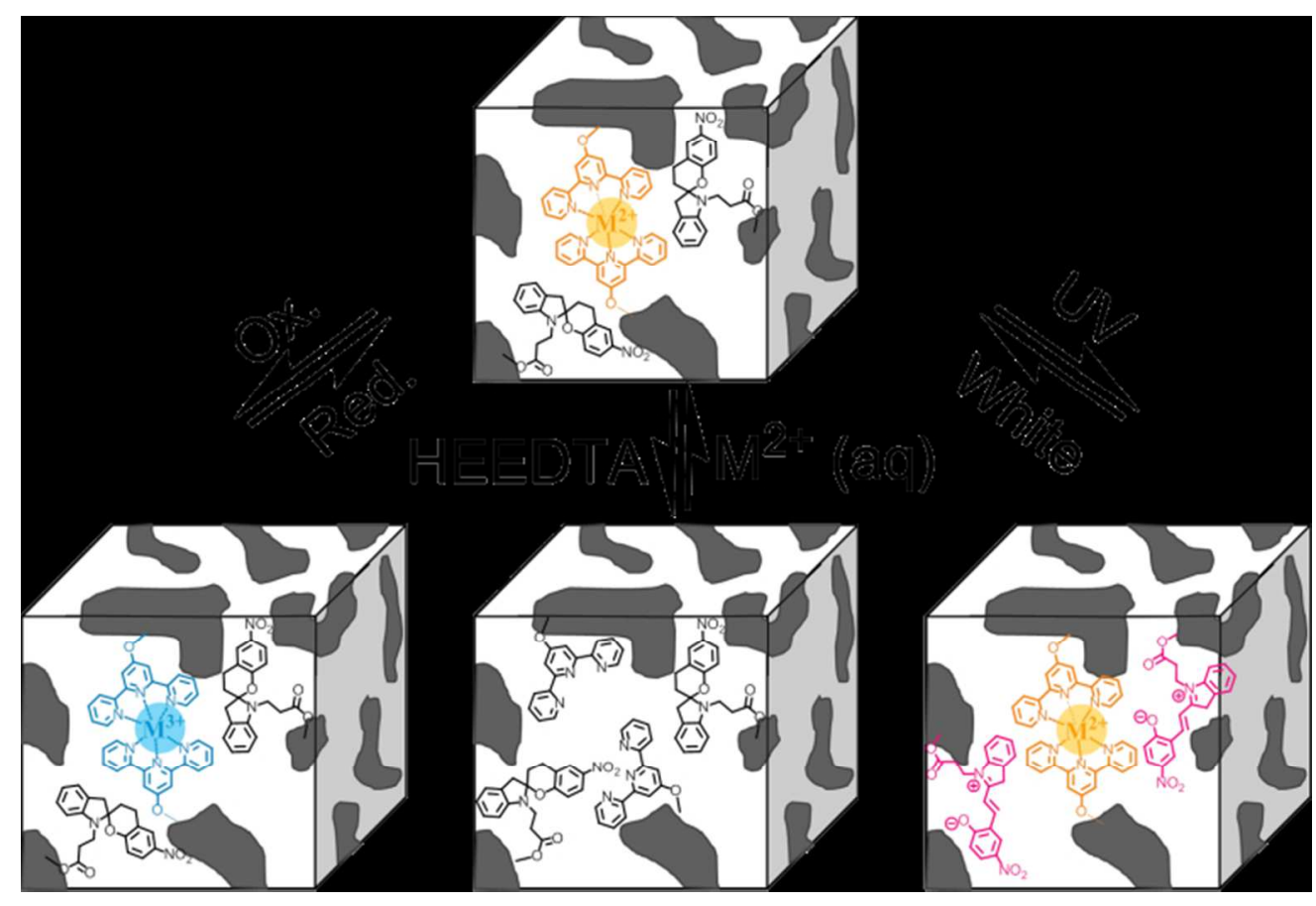

Table of contents figure

$87 \times 59 \mathrm{~mm}(220 \times 220$ DPI $)$ 


\section{Supplementary Information:}

\section{Terpyridine-functionalized redox-responsive hydrogels as platform for reversible multi-responsive polymer networks}

Katrin Schöller ${ }^{\mathrm{a}, \dagger}$, Claudio Toncelli ${ }^{\mathrm{a},} \uparrow$, Juliette Experton ${ }^{\mathrm{a}}$, Susanne Widmer ${ }^{\mathrm{a}}$, Daniel Rentsch ${ }^{\mathrm{b}}$, Aliaksei Vetushka $^{\mathrm{c}}$, Colin Martin ${ }^{\mathrm{d}}$, Manfred Heuberger ${ }^{\mathrm{a}}$, Catherine. E. Housecroft, ${ }^{\mathrm{d}}$ Edwin C. Constable ${ }^{\mathrm{d}}$, Luciano F. Boesel $^{\mathrm{a}, *}$, Lukas J. Scherer ${ }^{\mathrm{a}}$

${ }^{a}$ Empa, Swiss Federal Laboratories for Materials Science and Technology, Lerchenfeldstrasse 5, 9014 St.

Gallen, Switzerland

${ }^{\mathrm{b}}$ Empa, Swiss Federal Laboratories for Materials Science and Technology, Überlandstrasse 129, 8600

Dübendorf, Switzerland

${ }^{c}$ Laboratory of Nanostructures and Nanomaterials, Institute of Physics AS CR, Cukrovarnicka 10, 16200

Prague 6, Czech Republic

${ }^{\mathrm{d}}$ Department of Chemistry, University of Basel, Spitalstrasse 51, 4056 Basel, Switzerland

E-mail: Luciano.Boesel@empa.ch 


\section{NMR Experimental}

${ }^{1} \mathrm{H}$ and ${ }^{13} \mathrm{C}$ NMR spectra were obtained at $298 \mathrm{~K}$ on a Bruker Avance 400 (at 400.1 and $100.6 \mathrm{MHz}$ ) or Bruker Avance III-500 (at 500 and $126 \mathrm{MHz}$ ) spectrometer (Bruker Biospin AG, Fällanden, Switzerland). The $1 \mathrm{D}{ }^{1} \mathrm{H}$ and ${ }^{13} \mathrm{C}$ NMR spectra and the ${ }^{1} \mathrm{H}-{ }^{1} \mathrm{H}$, and ${ }^{1} \mathrm{H}-{ }^{13} \mathrm{C} 2 \mathrm{D}$ correlation experiments were performed at $298 \mathrm{~K}$ using a $5 \mathrm{~mm}$ BBI inverse probe equipped with z-gradient. All spectra were recorded with the Bruker standard pulse programs and parameter sets and the ${ }^{1} \mathrm{H} /{ }^{13} \mathrm{C}$ chemical shifts were referenced internally using the resonance signals of $\mathrm{CD}_{3} \mathrm{OD}$ at $3.31 / 49.0 \mathrm{ppm}$ or of $\mathrm{CDCl}_{3}$ at $7.26 / 77.0 \mathrm{ppm}$, respectively. Coupling constants $\mathrm{J}$ are reported in $\mathrm{Hz}$ and for ${ }^{1} \mathrm{H}$ NMR data coupling patterns are described as $\mathrm{s}=$ singlet, $\mathrm{d}=$ doublet, $\mathrm{t}=$ triplet, $\mathrm{q}=$ quartet, $\mathrm{m}=$ multiplet, $\mathrm{br}=$ broad. For ${ }^{13} \mathrm{C}$ NMR data $\mathrm{s}=$ quaternary carbon, $\mathrm{d}=\mathrm{CH}, \mathrm{t}=\mathrm{CH}_{2}, \mathrm{q}=\mathrm{CH}_{3}$ group and $\mathrm{w}=$ weak $\mathrm{HMBC}$ correlation.

\section{Synthesis of SP and TP1 monomers}

\section{Synthesis of SP:}

Spirobenzopyran SP was synthesized as reported in literature with an overall yield of $36 \%{ }^{1,2}$.

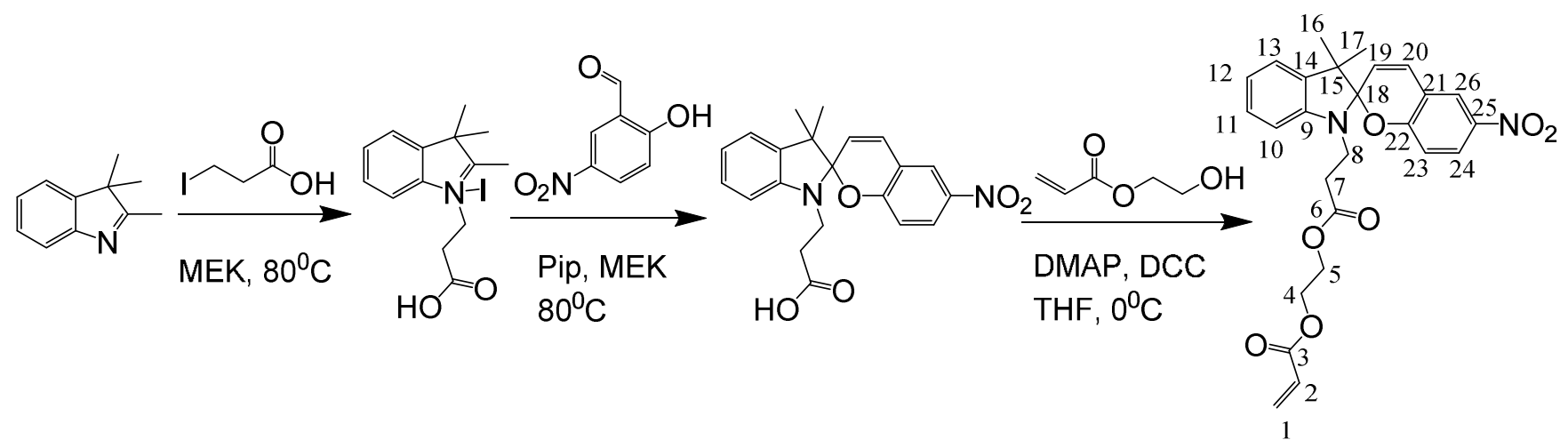

Scheme S-1. Synthesis of SP by coupling of an acrylic to the spirobenzopyran moiety 
${ }^{1} \mathrm{H}$ NMR $\left(\mathrm{CDCl}_{3}, 400.1 \mathrm{MHz}\right): \delta 8.01(\mathrm{dd}, \mathrm{J}=8.6+2.7,1 \mathrm{H}, \mathrm{H}-24) ; 7.99(\mathrm{~m}, 1 \mathrm{H}, \mathrm{H}-26) ; 7.20$ (m, 1H, H11); 7.08 (m, 1H, H-13); 6.92 (d, J = 10.4, 1H, H-20); 6.88 (m, 1H, H-12); 6.74 (d, J = 8.6, 1H, H-23); $6.61(\mathrm{~m}, 1 \mathrm{H}, \mathrm{H}-10) ; 6.39(\mathrm{dd}, \mathrm{J}=17.3+1.4,1 \mathrm{H}, \mathrm{H}-1 \mathrm{a}) ; 6.09$ (dd, J = 17.3+10.4, 1H, H-2); 5.86 (d, J = 10.4, 1H, H-19); 5.85 (dd, J = 10.4+1.4, 1H, H-1b); 4.31 (m, 2H, H-4); 4.24 (m, 2H, H-5); 3.64 (m, $1 \mathrm{H}$, H-8a); 3.52 (m, 1H, H-8b); 2.71 (m, 1H, H-7a); 2.6 (m, 1H, H-7b); 1.26 (s, 3H, H-16); 1.14 (s, 3H, H-17). ${ }^{13} \mathrm{C} \mathrm{NMR}\left(\mathrm{CDCl}_{3}, 100.6 \mathrm{MHz}\right): \delta 171.6$ (s, C-6); 165.8 (s, C-3); 159.3 (s, C-22); 146.3 (s, C-9); 141.1 (s, C-25); 136.0 (s, C-14); 131.5 (t, C-1); 128.4 (d, C-20); 127.9 (d, C-2); 127.8 (d, C-11); 125.7 (d, C-24); 122.7 (d, C-26); 122.0 (d, C-19); 121.9 (d, C-13); 119.9 (d, C-12); 118.6 (s, C-21); 115.3 (d, C-23); 106.8 (d, C-10); 106.7 (s, C-18); 62.2 (t, C-5); 62.0 (t, C-4); 52.9 (s, C-15); 39.1 (t, C-8); 33.4 (t, C-7); 25.8 (q, C-17); 19.8 (q, C-16).

${ }^{1} \mathrm{H}-{ }^{13} \mathrm{C}$ HMBC correlations: H-1a $\rightarrow$ C-(2w, 3); H-1b $\rightarrow$ C-(3); H-2 $\rightarrow$ C-(3w); H-4 $\rightarrow$ C-(3, 5); H-5 $\rightarrow$ $\mathrm{C}-(4,6) ; \mathrm{H}-7 \mathrm{a} \rightarrow \mathrm{C}-(6,8) ; \mathrm{H}-7 \mathrm{~b} \rightarrow \mathrm{C}-(6,8) ; \mathrm{H}-8 \mathrm{a} \rightarrow \mathrm{C}-(6,7,9,18) ; \mathrm{H}-8 \mathrm{~b} \rightarrow \mathrm{C}-(6,7 \mathrm{w}, 9,18 \mathrm{w}) ; \mathrm{H}-10 \rightarrow$ $\mathrm{C}-(12,14) ; \mathrm{H}-11 \rightarrow \mathrm{C}-(9,13) ; \mathrm{H}-12 \rightarrow \mathrm{C}-(10,13,14) ; \mathrm{H}-13 \rightarrow \mathrm{C}-(9,11,12 \mathrm{w}, 15) ; \mathrm{H}-16 \rightarrow \mathrm{C}-(14,15$, $17,18) ; \mathrm{H}-17 \rightarrow \mathrm{C}-(14,15,16,18) ; \mathrm{H}-19 \rightarrow \mathrm{C}-(18,21) ; \mathrm{H}-20 \rightarrow \mathrm{C}-(18,21,22,26)$; H-23 $\rightarrow$ C-(21, 22w, $25)$; H-24 $\rightarrow$ C-(22, 25w, 26); H-26 $\rightarrow$ C- $(20,22,24,25 w)$. Note: We observed no ${ }^{3} J$ correlation from H19 to C-15, probably due to an unfavorable (small) bond angle of H-19/C-19/C-18/C-15.

${ }^{1} \mathrm{H}-{ }^{1} \mathrm{H}$ DQF-COSY correlations: H-1a $\rightarrow \mathrm{H}-(1 \mathrm{~b}, 2)$; H-1b $\rightarrow \mathrm{H}-(1 \mathrm{a}, 2)$; H-2 $\rightarrow$ H-(2); H-4 $\rightarrow$ H-(5); H-5 $\rightarrow \mathrm{H}-(4) ; \mathrm{H}-7 \mathrm{a} \rightarrow \mathrm{H}-(7 \mathrm{~b}, 8 \mathrm{a}, 8 \mathrm{~b}) ; \mathrm{H}-7 \mathrm{~b} \rightarrow \mathrm{H}-(7 \mathrm{a}, 8 \mathrm{a}, 8 \mathrm{~b}) ; \mathrm{H}-8 \mathrm{a} \rightarrow \mathrm{H}-(7 \mathrm{a}, 7 \mathrm{~b}, 8 \mathrm{~b}) ; \mathrm{H}-8 \mathrm{~b} \rightarrow \mathrm{H}-(7 \mathrm{a}, 7 \mathrm{~b}, 8 \mathrm{a}) ;$ $\mathrm{H}-10 \rightarrow \mathrm{H}-(11) ; \mathrm{H}-11 \rightarrow \mathrm{H}-(10,12) ; \mathrm{H}-12 \rightarrow \mathrm{H}-(11,13) ; \mathrm{H}-13 \rightarrow \mathrm{H}-(12) ; \mathrm{H}-19 \rightarrow \mathrm{H}-(20) ; \mathrm{H}-20 \rightarrow \mathrm{H}-$ (19); H-23 $\rightarrow$ H-(24); H-24 $\rightarrow$ H-(23).

IR $\left(\mathrm{cm}^{-1}\right): 1733.0(\mathrm{~s}), 1622.4(\mathrm{~m}), 1483.0(\mathrm{~m}), 1407.6(\mathrm{~m}), 1248.2(\mathrm{~s}), 1164.0(\mathrm{~s}), 1023.5(\mathrm{~m})$, $964.0(\mathrm{~m}), 911.7(\mathrm{~m}), 837.0(\mathrm{~m}), 797.7(\mathrm{~m})$.

$\mathrm{UV}(\mathrm{nm}): 585,620$

MS (pos., m/z): 469.16

Elem. Anal.: calcd: [C] 71.78\%, [H] 5.16\%, [N] 5.98\%, obsd: [C] 68.11\%, [H] 5.29\%, [N] $5.39 \%$. 

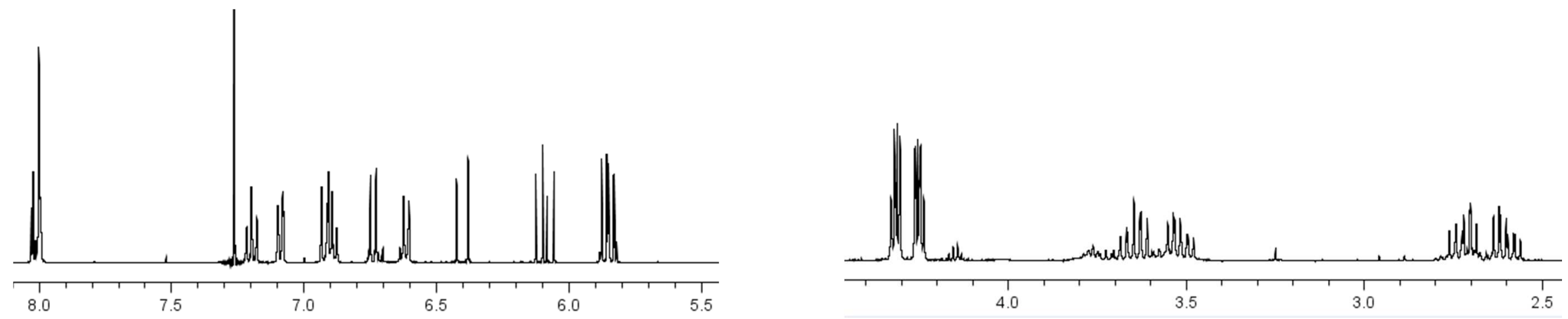

Figure S-1a. Regions of interest of ${ }^{1} \mathrm{H}$ NMR spectra of SP monomer (in $\mathrm{CDCl}_{3}$ )
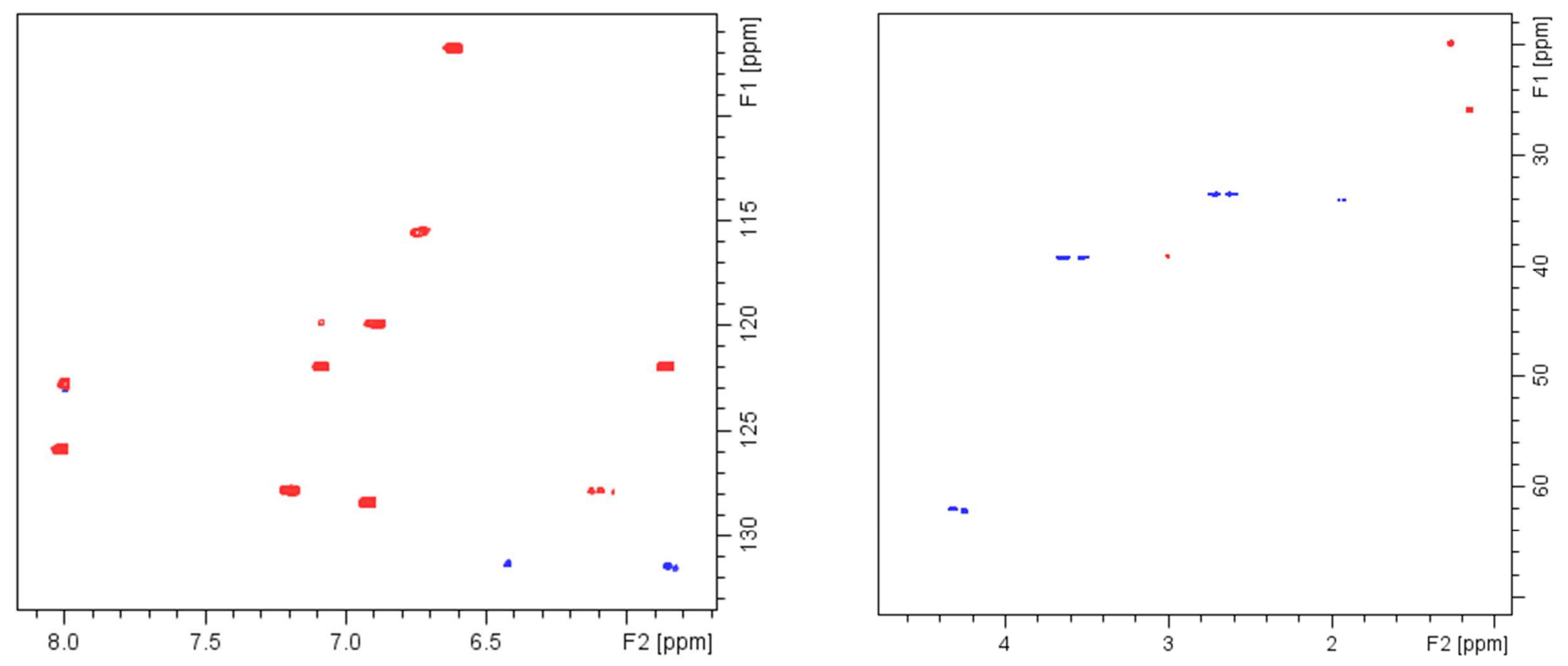

Figure S-1b. Regions of interest of ${ }^{1} \mathrm{H}^{-13} \mathrm{C}$ HSQC NMR spectra of SP monomer (in $\mathrm{CDCl}_{3}$ ) 

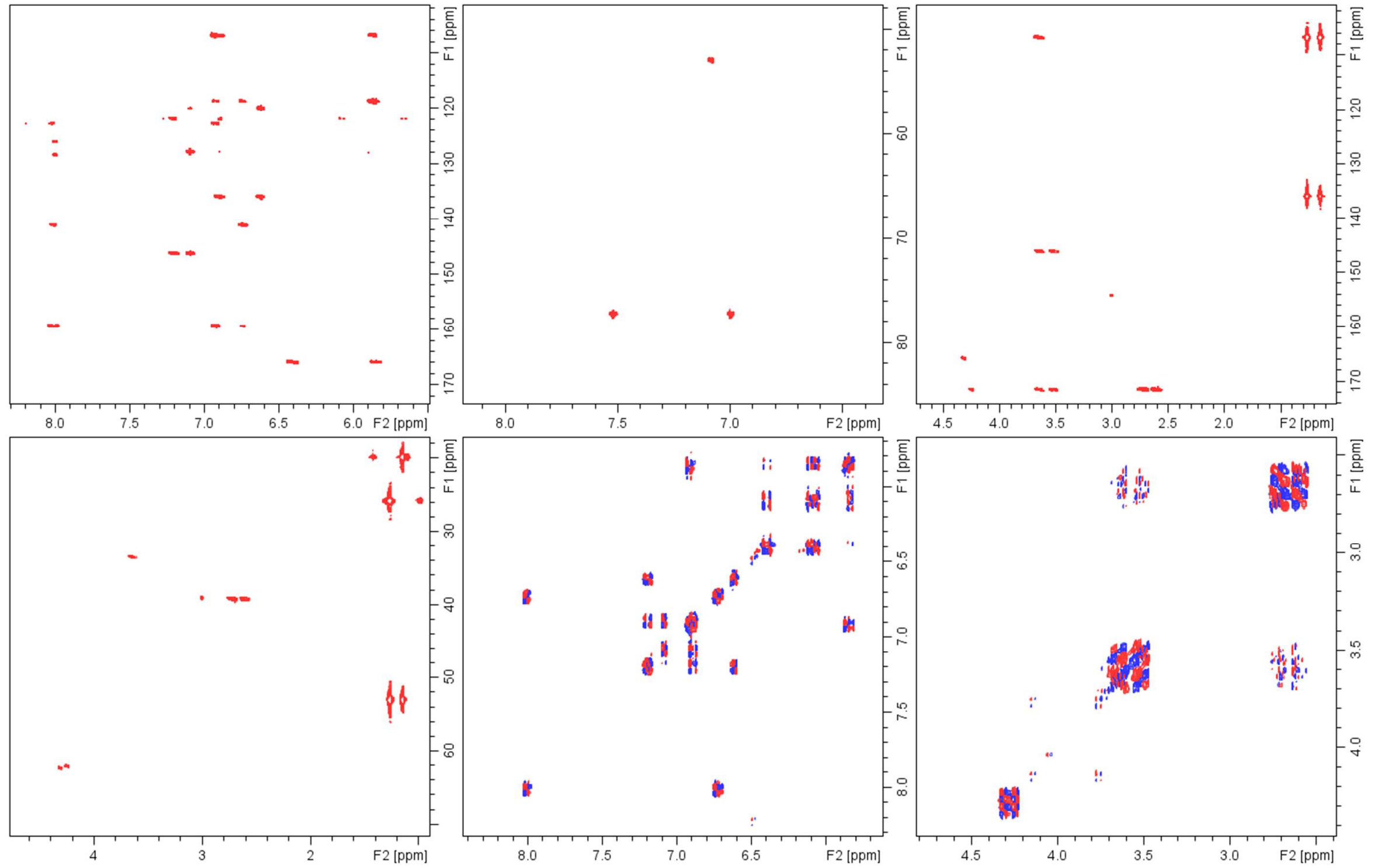

Figure S-1c. Regions of interest of ${ }^{1} \mathrm{H}_{-}{ }^{13} \mathrm{C} \mathrm{HMBC}$ and ${ }^{1} \mathrm{H}-{ }^{1} \mathrm{H}$ DQF-COSY NMR spectra of SP monomer (in $\mathrm{CDCl}_{3}$ ) 


\section{Synthesis of TP1}

Terpyridine 1 (TP1) synthesized according to literature (49\% yield $)^{3}$.

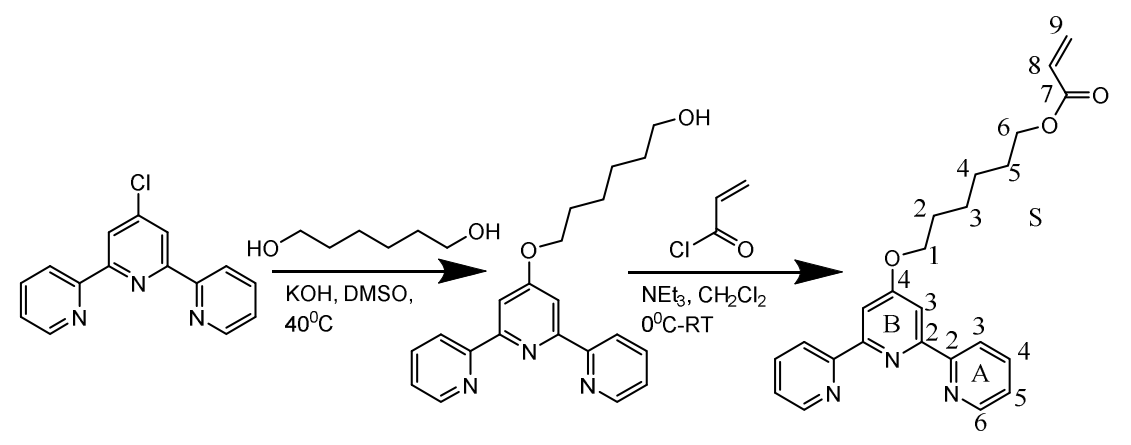

Scheme S-2. Synthesis of TP1 via coupling of hexane-1,6-diol with terpyridine followed by addition of an acrylic monomer.

${ }^{1} \mathrm{H}$ NMR $\left(\mathrm{CDCl}_{3}, 400.1 \mathrm{MHz}\right): \delta 8.72(\mathrm{ddd}, \mathrm{J}=4.8+1.8+0.8,2 \mathrm{H}, \mathrm{H}-\mathrm{A} 6) ; 8.66(\mathrm{ddd}, \mathrm{J}=7.8+1.1+0.8,2 \mathrm{H}$, H-A3); 8.06 (s, 2H, H-B3); 7.89 (ddd, J = 7.8+7.5+1.8, 2H, H-A4); 7.37 (ddd, J = 7.5+4.8+1.1, 2H, HA5); 6.40 (dd, J = 17.3+1.5, 1H, H-S9a); 6.12 (dd, J = 17.3+10.4, 1H, H-S8); 5.80 (dd, J = 10.4+1.5, 1H, H-S9b); 4.27 (t, J = 6.4, 2H, H-S1); 4.18 (t, J = 6.7, 2H, H-S6); 1.88 (m, 2H, H-S2); 1.72 (m, 2H, H-S5); 1.55 (m, 2H, H-S3); 1.48 (m, 2H, H-S4).

${ }^{13} \mathrm{C}$ NMR $\left(\mathrm{CDCl}_{3}, 100.6 \mathrm{MHz}\right): \delta 167.5$ (s, C-B4); 166.3 (s, C-S7); 156.3 (s, C-B2); 155.5 (s, C-A2); 148.5 (d, C-A6); 137.5 (d, C-A4); 130.5 (t, C-S9); 128.7 (d, C-S8); 124.0 (d, C-A5); 121.7 (d, C-A3); 107.9 (d, C-B3); 68.3 (t, C-S1); 64.5 (t, C-S6); 28.9 (t, C-S2); 28.5 (t, C-S5); 20.7 (t, C-S4); 20.7 (t, CS3).

${ }^{1} \mathrm{H}-{ }^{13} \mathrm{C}$ HMBC correlations: H-A3 $\rightarrow$ C-(A5, B2); H-A4 $\rightarrow$ C-(A2, A6); H-A5 $\rightarrow$ C-(A3, A6); H-A6 $\rightarrow$ $\mathrm{C}-(\mathrm{A} 2, \mathrm{~A} 4, \mathrm{~A} 5) ; \mathrm{H}-\mathrm{B} 3 \rightarrow \mathrm{C}-(\mathrm{A} 2, \mathrm{~B} 3, \mathrm{~B} 4) ; \mathrm{H}-\mathrm{S} 1 \rightarrow \mathrm{C}-(\mathrm{B} 4, \mathrm{~S} 2, \mathrm{~S} 3)$; H-S2 $\rightarrow$ C-(S1, S3, S4); H-S3 $\rightarrow$ C$(\mathrm{S} 1, \mathrm{~S} 2, \mathrm{~S} 4, \mathrm{~S} 5) ; \mathrm{H}-\mathrm{S} 4 \rightarrow \mathrm{C}-(\mathrm{S} 2, \mathrm{~S} 3, \mathrm{~S} 5, \mathrm{~S} 6) ; \mathrm{H}-\mathrm{S} 5 \rightarrow \mathrm{C}-(\mathrm{S} 3, \mathrm{~S} 4, \mathrm{~S} 6) ; \mathrm{H}-\mathrm{S} 6 \rightarrow \mathrm{C}-(\mathrm{S} 4, \mathrm{~S} 5, \mathrm{~S} 7) ; \mathrm{H}-\mathrm{S} 8 \rightarrow$ $\mathrm{C}-(\mathrm{S} 7, \mathrm{~S} 9) ; \mathrm{H}-\mathrm{S} 9 \mathrm{a} \rightarrow \mathrm{C}-(\mathrm{S} 7, \mathrm{~S} 8) ; \mathrm{H}-\mathrm{S} 9 \mathrm{~b} \rightarrow \mathrm{C}-(\mathrm{S} 7, \mathrm{~S} 8)$.

${ }^{1} \mathrm{H}-{ }^{1} \mathrm{H}$ DQF-COSY correlations: H-A3 $\rightarrow$ H-(A4); H-A4 $\rightarrow$ H-(A3, A5); H-A5 $\rightarrow$ H-(A4, A6); H-A6 $\rightarrow$ $\mathrm{H}-(\mathrm{A} 5) ; \mathrm{H}-\mathrm{S} 1 \rightarrow \mathrm{H}-(\mathrm{S} 2) ; \mathrm{H}-\mathrm{S} 2 \rightarrow \mathrm{H}-(\mathrm{S} 1, \mathrm{~S} 3) ; \mathrm{H}-\mathrm{S} 3 \rightarrow \mathrm{H}-(\mathrm{S} 2, \mathrm{~S} 4)$; H-S4 $\rightarrow$ H-(S3, S5); H-S5 $\rightarrow$ H-(S4, S6); H-S6 $\rightarrow$ H-(S5); H-S8 $\rightarrow$ H-(S9a, S9b); H-S9a $\rightarrow$ H-(S8, S9b); H-S9b $\rightarrow$ H-(S8, S9a). 

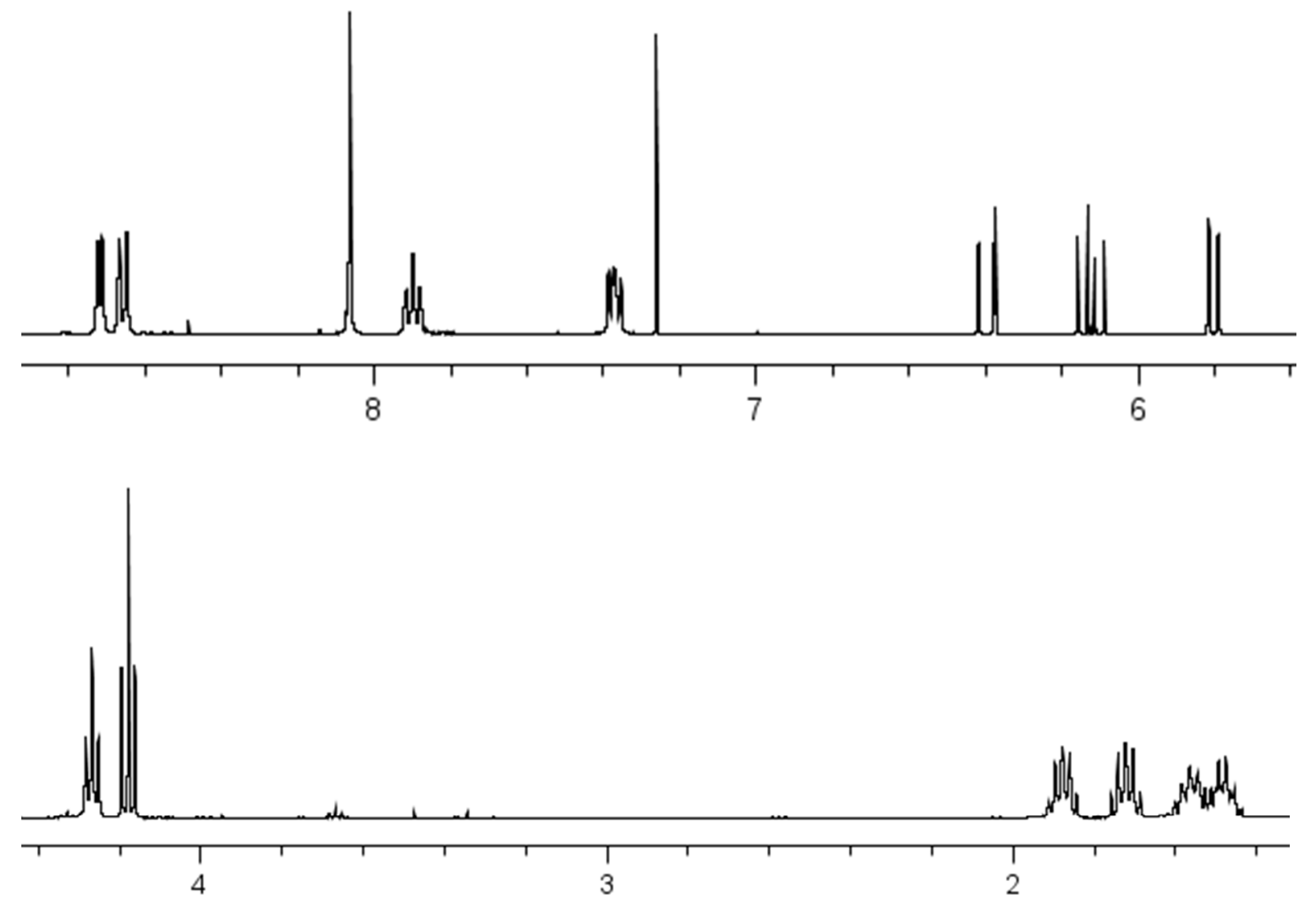

Figure S-2a. Regions of interest of ${ }^{1} \mathrm{H}$ NMR spectra of TP monomer (in $\mathrm{CDCl}_{3}$ 

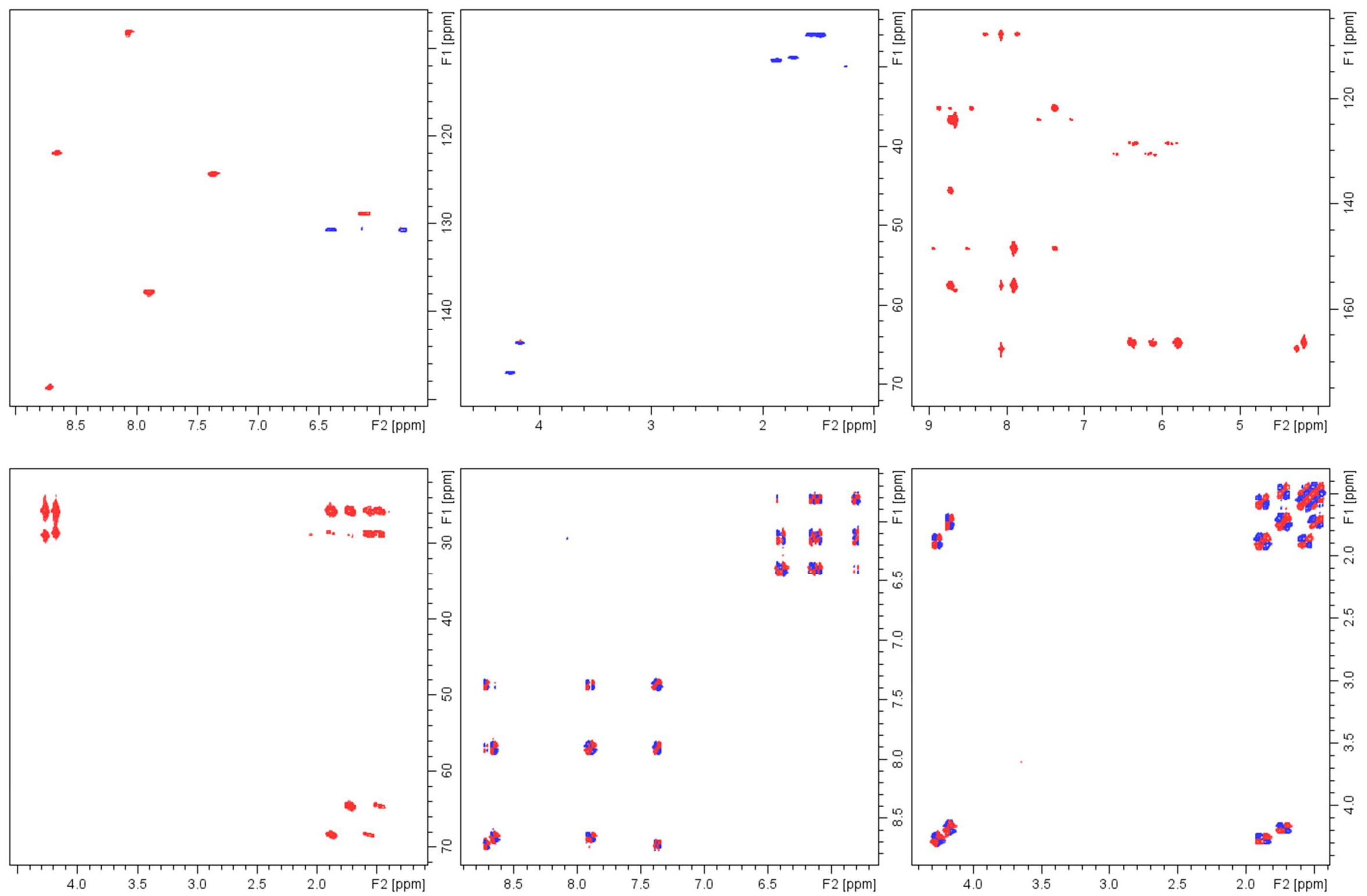

Figure S-2b. Regions of interest of ${ }^{1} \mathrm{H}-{ }^{13} \mathrm{C} \mathrm{HSQC}, \mathrm{HMBC}$ and ${ }^{1} \mathrm{H}-{ }^{1} \mathrm{H}$ DQF-COSY NMR spectra of TP monomer (in $\left.\mathrm{CDCl}_{3}\right)$ 


\section{Characterization of TP1 complexes with Fe(II) and Co(II)}

\section{Synthesis and characterization of TP1/ Fe(II) complex}

Ligand TP1 (69.8 mg, $0.173 \mathrm{mmol})$ and iron(II) chloride $(11 \mathrm{mg}, 0.0865 \mathrm{mmol})$ were added together in a ratio of 2:1 (ligand/metal) in methanol $(10 \mathrm{~mL})$. The reaction mixture changed to dark purple immediately and was stirred for 30 minutes. The solution was treated with excess ammonium hexafluorophosphate and water $(3 \mathrm{~mL})$ to precipitate $\left[\mathrm{Fe}(\mathrm{TP} 1)_{2}\right]\left[\mathrm{PF}_{6}\right]_{2}$ as a purple solid. The suspension was filtered over Celite and washed with water, ethanol and diethyl ether to remove impurities. The pure purple product was washed off Celite with acetonitrile and dried under vacuum.

Yield: $62 \mathrm{mg}, 0.072 \mathrm{mmol}, 83 \%$.

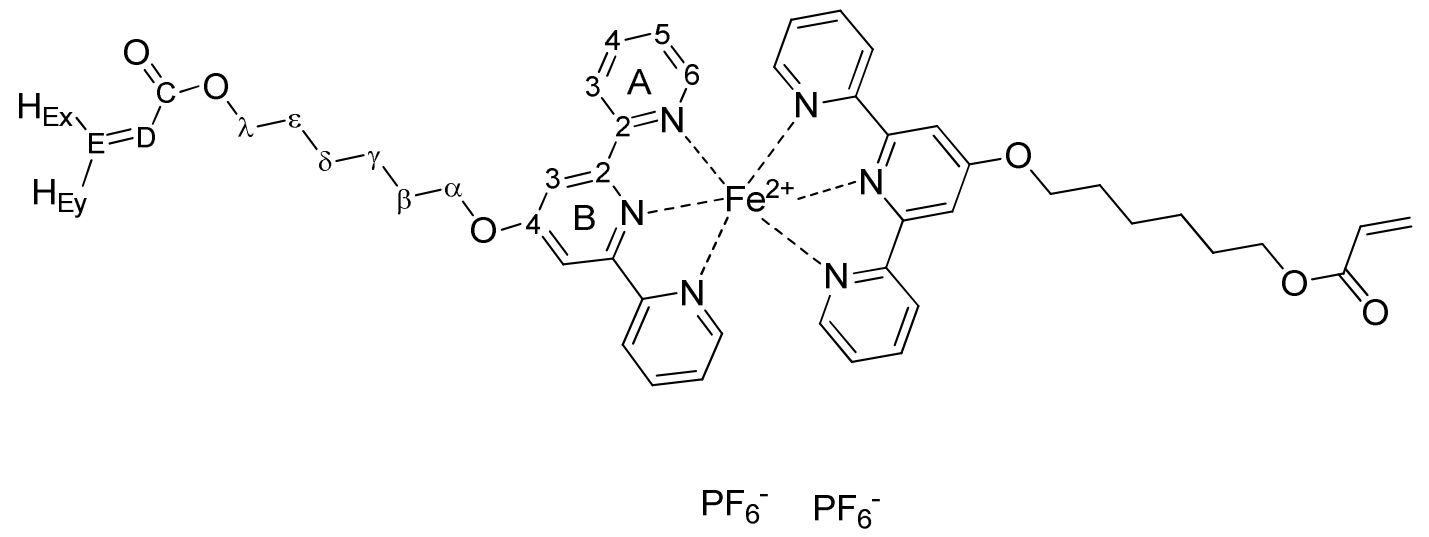

Scheme S-3. Chemical structure of TP1 complex with Fe(II) with labelled positions used for assignments of ${ }^{1} \mathrm{H}$ and ${ }^{13} \mathrm{C}$ NMR data.

${ }^{1} \mathrm{H}-\mathrm{NMR}\left(500 \mathrm{MHz}, \mathrm{CD}_{3} \mathrm{CN}, 25^{\circ} \mathrm{C}\right) \delta: 8.46\left(\mathrm{~s}, 4 \mathrm{H}, \mathrm{H}_{\mathrm{B} 3}\right), 8.44\left(\mathrm{~m}, 4 \mathrm{H}, \mathrm{H}_{\mathrm{A} 3}\right), 7.88\left(\mathrm{~m}, 4 \mathrm{H}, \mathrm{H}_{\mathrm{A} 4}\right)$, $7.16\left(\mathrm{~m}, 4 \mathrm{H}, \mathrm{H}_{\mathrm{A} 6}\right), 7.09\left(\mathrm{~m}, 4 \mathrm{H}, \mathrm{H}_{\mathrm{A} 5}\right), 6.39\left(\mathrm{dd}, 2 \mathrm{H}, \mathrm{J}=17.4\right.$ and $\left.1.5 \mathrm{~Hz}, \mathrm{H}_{\mathrm{Ey}}\right), 6.20(\mathrm{dd}, 2 \mathrm{H}, \mathrm{J}=$ 17.4 and $\left.10.5 \mathrm{~Hz}, \mathrm{H}_{\mathrm{D}}\right), 5.88\left(\mathrm{dd}, 2 \mathrm{H}, \mathrm{J}=10.5\right.$ and $\left.1.5 \mathrm{~Hz}, \mathrm{H}_{\mathrm{Ex}}\right), 4.63\left(\mathrm{t}, 4 \mathrm{H}, \mathrm{J}=6.5 \mathrm{~Hz}, \mathrm{H}_{\alpha}\right), 4.26$ $\left(\mathrm{t}, 4 \mathrm{H}, \mathrm{J}=6.7 \mathrm{~Hz}, \mathrm{H}_{\lambda}\right), 2.11\left(\mathrm{~m}, 4 \mathrm{H}, \mathrm{H}_{\beta}\right), 1.83\left(\mathrm{~m}, 4 \mathrm{H}, \mathrm{H}_{\varepsilon}\right), 1.74\left(\mathrm{~m}, 4 \mathrm{H}, \mathrm{H}_{\gamma}\right), 1.63\left(\mathrm{~m}, 4 \mathrm{H}, \mathrm{H}_{\delta}\right)$. 
${ }^{13} \mathrm{C}\left\{{ }^{1} \mathrm{H}\right\}-\mathrm{NMR}\left(126 \mathrm{MHz}, \mathrm{CD}_{3} \mathrm{CN}, 25^{\circ} \mathrm{C}\right) \delta: 168.0\left(\mathrm{C}_{\mathrm{B} 4}\right), 166.0\left(\mathrm{C}_{\mathrm{C}}\right), 160.8\left(\mathrm{C}_{\mathrm{B} 2}\right), 158.1\left(\mathrm{C}_{\mathrm{A} 2}\right)$, $153.3\left(\mathrm{C}_{\mathrm{A} 6}\right), 138.4\left(\mathrm{C}_{\mathrm{A} 4}\right), 130.3\left(\mathrm{C}_{\mathrm{E}}\right), 128.6\left(\mathrm{C}_{\mathrm{D}}\right), 127.1\left(\mathrm{C}_{\mathrm{A} 5}\right), 123.5\left(\mathrm{C}_{\mathrm{A} 3}\right), 111.3\left(\mathrm{C}_{\mathrm{B} 3}\right), 70.5\left(\mathrm{C}_{\alpha}\right)$, $64.3\left(\mathrm{C}_{\lambda}\right), 28.5\left(\mathrm{C}_{\beta}\right), 28.3\left(\mathrm{C}_{\varepsilon}\right), 25.4\left(\mathrm{C}_{\delta}\right), 25.3\left(\mathrm{C}_{\gamma}\right)$.

Elemental Analysis: Calculated for $\mathrm{C}_{48} \mathrm{H}_{50} \mathrm{~F}_{12} \mathrm{FeN}_{6} \mathrm{O}_{6} \mathrm{P}_{2}$ : C, 50.01; H, 4.37; N, 7.29. Found: C, 49.83; H, 4.86; N, 7.45.

ESI-MS: m/z 431.3 m.u. [M-2PF $]^{2+}$ (calc. 431.3 m.u.).

\section{TP1/Co(II) complex characterization}

In Fig. S-3a-S-3c regions of interest of the ${ }^{1} \mathrm{H},{ }^{1} \mathrm{H}-{ }^{13} \mathrm{C}$ HSQC and ${ }^{1} \mathrm{H}-{ }^{1} \mathrm{H}$ DQF-COSY NMR spectra of the paramagnetic $\mathrm{Co}(\mathrm{II}) / \mathrm{TP} 1$ complex are shown. Exceptionally large and unusual ${ }^{1} \mathrm{H}$ and ${ }^{13} \mathrm{C}$ NMR chemical shift values of up to 110 and 490 ppm, respectively, were determined for the Co(II) complex. Unfortunately, the full chemical shift assignment of the Co(II)/TP1 complex is not really trivial, since owing to the considerably broad ${ }^{1} \mathrm{H}$ NMR signals the recoding of e.g. ${ }^{1} \mathrm{H}-{ }^{13} \mathrm{C}$ long range correlation experiments completely failed. Nevertheless, the assignment of ${ }^{1} \mathrm{H} \&{ }^{13} \mathrm{C}$ chemical shifts was possible i) over a walk through the DQF-COSY spectra (see Fig S-3c) from Position 1 (signal at $15.1 \mathrm{ppm}$ ) to 6 of the side chain (S) and ii) from the corresponding cross peaks in the HSQC spectrum the ${ }^{13} \mathrm{C}$ chemical shifts were evaluated (Fig. S-3b). The assignment of the terpyridine moiety next to the paramagnetic center was much more difficult since the excitation and as well, the inversion of magnetization in the $2 \mathrm{D}$ NMR pulse sequences of that wide region in the ${ }^{1} \mathrm{H}$ and ${ }^{13} \mathrm{C}$ dimensions is a prerequisite. The connectivity of H-3A, H-4A and H-5A was monitored by correlations of the resonance at 6.62 ppm to protons at 69.4 and 33.9 ppm (Fig. S-3c). From chemical shift reasons, the $\approx 250 \mathrm{~Hz}$ broad resonance at 109 ppm was assigned to H-6A and the remaining signal at 73.7 ppm must belong to $\mathrm{H}-3 \mathrm{~A}$. This ${ }^{1} \mathrm{H}$ NMR chemical shift assignments perfectly matches the data given by E.C. Constable et al. ${ }^{4}$ for a Co(II) complex with a TP ligand substituted by a methoxy group at the B4 position. The ${ }^{1} \mathrm{H}_{-}{ }^{13} \mathrm{C}$ HSQC NMR spectra (see Fig. S$3 b)$ both were recorded without multiplicity editing and omitting shaped pulses to enable the excitation of the biggest possible spectral regions. By varying the widths and the carrier frequencies in the ${ }^{13} \mathrm{C}$ dimension the unusually high ${ }^{13} \mathrm{C}$ chemical shifts of 493.0 (C-65), 370.4 (C-3B) and 346.4 (C-A3) were unambiguously assigned. These values are in very good agreement with the data given for a similar 
compound (Co(II)-complex of ligand 9 (p. 149) $)^{5}$, which to our knowledge was not published so far. In this work, the ${ }^{13} \mathrm{C}$ chemical shifts were assigned over selectively proton decoupled $1 \mathrm{D}{ }^{13} \mathrm{C} N M R$ experiments. It must be mentioned that in our case the recording of $1 \mathrm{D}{ }^{13} \mathrm{C} \mathrm{NMR}$ experiments was not possible, since higher concentrated NMR solutions tented to spontaneous polymerization due to the presence of the terminal acrylate group. Due to the large line width, we did not observe a correlation of $\mathrm{H}-6 \mathrm{~A}$ to any carbon in the HSQC NMR experiment and it is clear that we were not able determine the ${ }^{13} \mathrm{C}$ chemical shift data for all quaternary carbons as well.

${ }^{1} \mathrm{H}$ NMR (MeOD,400.1 MHz): $\delta 108.9$ (s (br), 2H, H-A6); 73.7 (s (br), 2H, H-B3); 69.4 (s (br), 2H, HA3); 33.9 (s (br), 2H, H-A5); 15.1 (m (br), 2H, H-S1); 7.51 (m (br), 2H, H-S2); 7.05 (dd, J = 17.4+2.5, 1H, H-S9a); 6.98 (dd, J = 17.4+9.6, 1H, H-S8); 6.62 (s (br), 2H, H-A4); 6.35 (m (br), 2H, H-S3); 6.28 (dd, J = 9.6+2.5, 1H, H-S9b); 5.98 (t, J = 6.5, 2H, H-S6); 4.74 (m, 2H, H-S4); 4.11 (m, 2H, H-S5).

${ }^{13} \mathrm{C}$ NMR (MeOD, $100.6 \mathrm{MHz}$ ): $\delta 493$ (d, C-A5); 370.4 (d, C-B3); 346.4 (d, C-A3); 160.6 (d, C-A4); 132.0 (t, C-S9); 130.5 (d, C-S8); 80.9 (t, C-S1); 67.4 (t, C-S6); 38.5 (t, C-S2); 32.1 (t, C-S5); 31.3 (t, CS3); 30.0 (t, C-S4).

${ }^{1} \mathrm{H}-{ }^{1} \mathrm{H}$ DQF-COSY correlations: H-A3 $\rightarrow \mathrm{H}-(\mathrm{A} 4)$; H-A4 $\rightarrow$ H-(A3, A5); H-A5 $\rightarrow$ H-(A4); H-S1 $\rightarrow$ H$(\mathrm{S} 2) ; \mathrm{H}-\mathrm{S} 2 \rightarrow \mathrm{H}-(\mathrm{S} 1, \mathrm{~S} 3) ; \mathrm{H}-\mathrm{S} 3 \rightarrow \mathrm{H}-(\mathrm{S} 2, \mathrm{~S} 4) ; \mathrm{H}-\mathrm{S} 4 \rightarrow \mathrm{H}-(\mathrm{S} 3, \mathrm{~S} 5) ; \mathrm{H}-\mathrm{S} 5 \rightarrow \mathrm{H}-(\mathrm{S} 4, \mathrm{~S} 6) ; \mathrm{H}-\mathrm{S} 6 \rightarrow \mathrm{H}-$ (S5); H-S8 $\rightarrow$ H-(S9a, S9b); H-S9a $\rightarrow$ H-(S8, S9b); H-S9b $\rightarrow$ H-(S8, S9a). 

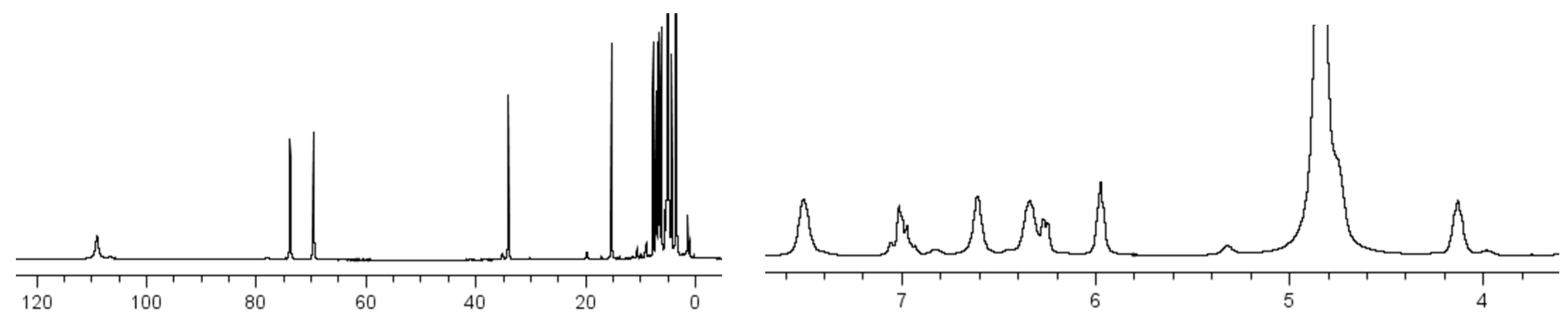

Figure S-3a. Full and enlarged region of ${ }^{1} \mathrm{H}$ NMR spectrum of paramagnetic TP1/Co(II) (in $\mathrm{CD}_{3} \mathrm{OD}$ )
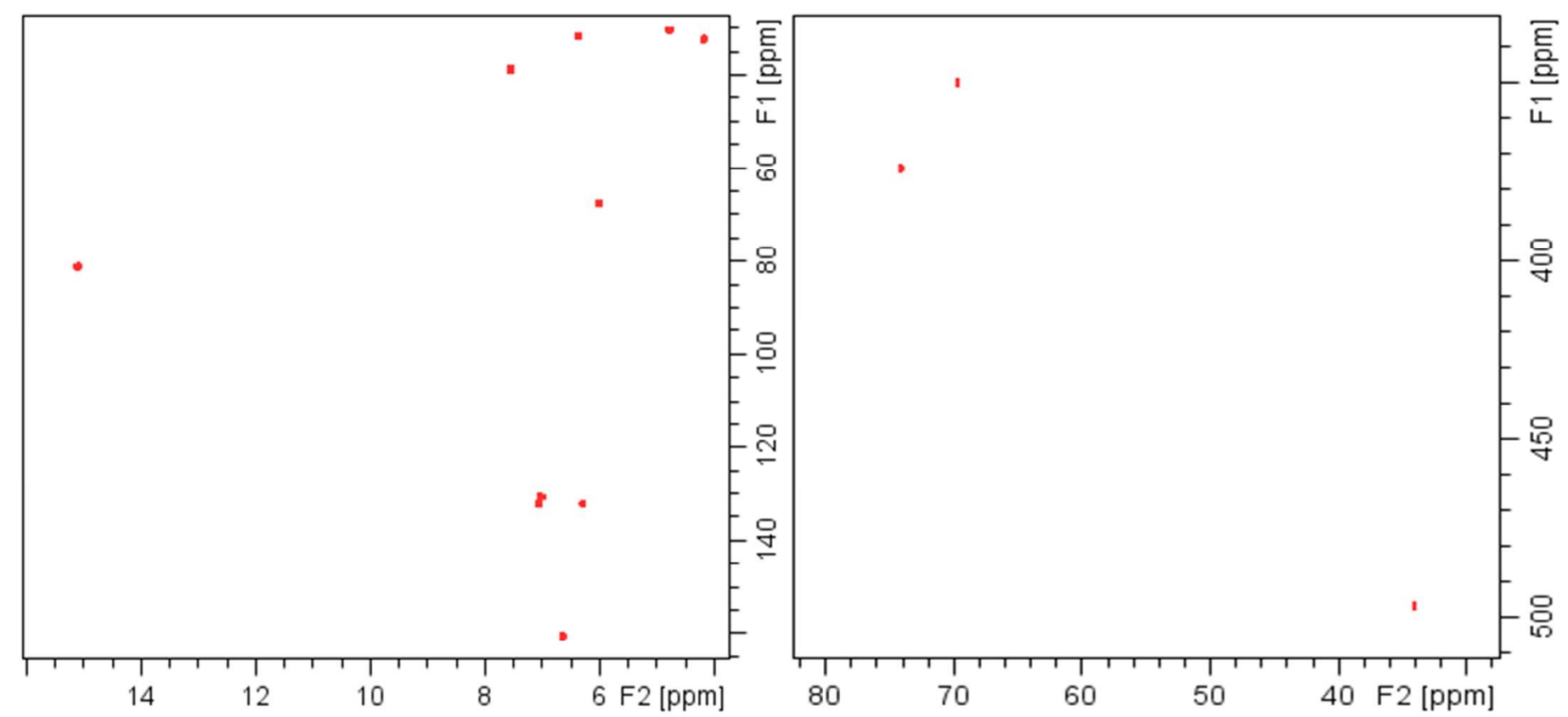

Figure S-3b. Regions of interest of ${ }^{1} \mathrm{H}_{-}{ }^{13} \mathrm{C}$ HSQC NMR spectrum of paramagnetic TP1/Co(II) (in $\mathrm{CD}_{3} \mathrm{OD}$ ) 


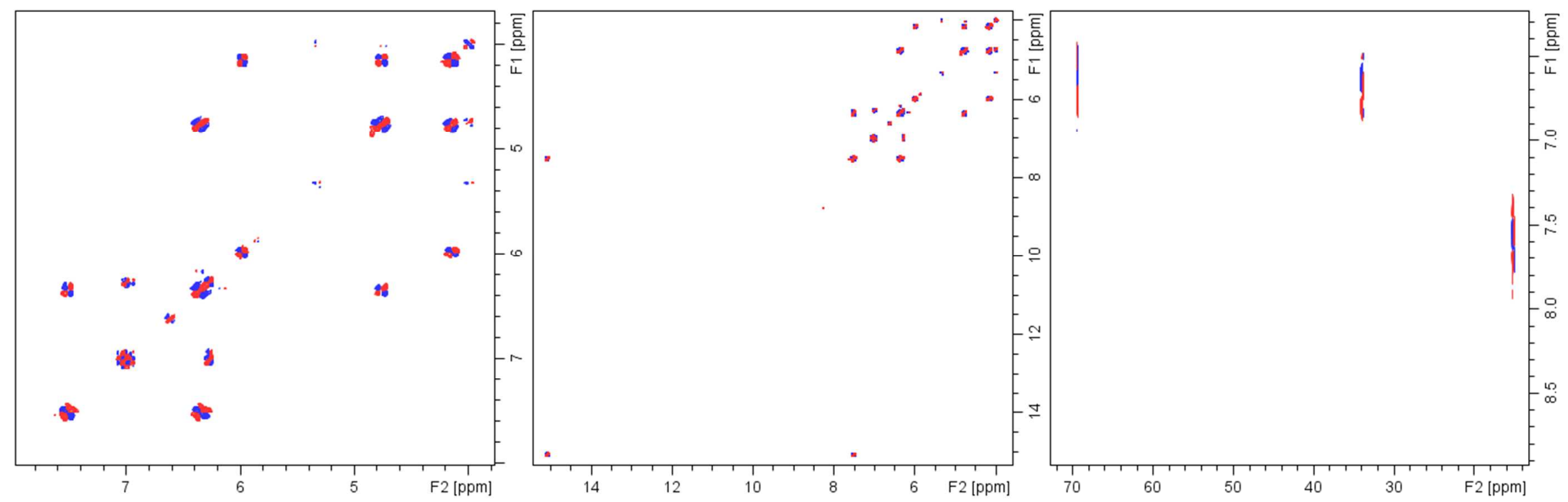

Figure S-3c. Regions of interest of ${ }^{1} \mathrm{H}^{-1} \mathrm{H}$ DQF-COSY NMR spectra of paramagnetic TP1/Co(II) (in $\left.\mathrm{CD}_{3} \mathrm{OD}\right)$ 


\section{Characterization of amphiphilic co-networks (APCNs) functionalized with TP1}

\section{Quantification of TP1 inside the membranes}

Four membranes with TP1 (10.3 mg, $0.026 \mathrm{mmol})$ were synthesized according to the method given in the experimental section and immersed for $12 \mathrm{~h}$ in $45 \mathrm{ml}$ of a THF/water 50/50 vol-\% solution. Then, $2.5 \mathrm{ml}$ of this solution were analyzed by UV-Vis in a cuvette while stirring at $30^{\circ} \mathrm{C}$. The amount of TP1 inside the solution was calibrated by adding progressively $5 \mu \mathrm{l}$, then $10 \mu \mathrm{l}$ of a $0.1 \mathrm{~g} / \mathrm{FeCl}_{2} \cdot 4 \mathrm{H}_{2} \mathrm{O}$ aqueous solution. After each addition, the solution was stirred for $2 \mathrm{~min}$ and the absorbance at $556 \mathrm{~nm}$ was registered with a Varian 50Bio/50MPR system. The intersection of the two tangents at the beginning and the end of the curve gives an equivalence point at $4.0 .10^{-5} \mathrm{mmol}$ of $\mathrm{FeCl}_{2} \cdot 4 \mathrm{H}_{2} \mathrm{O}$ corresponding to $5.64 \%$ of the total mass of TP1 that did not polymerize.

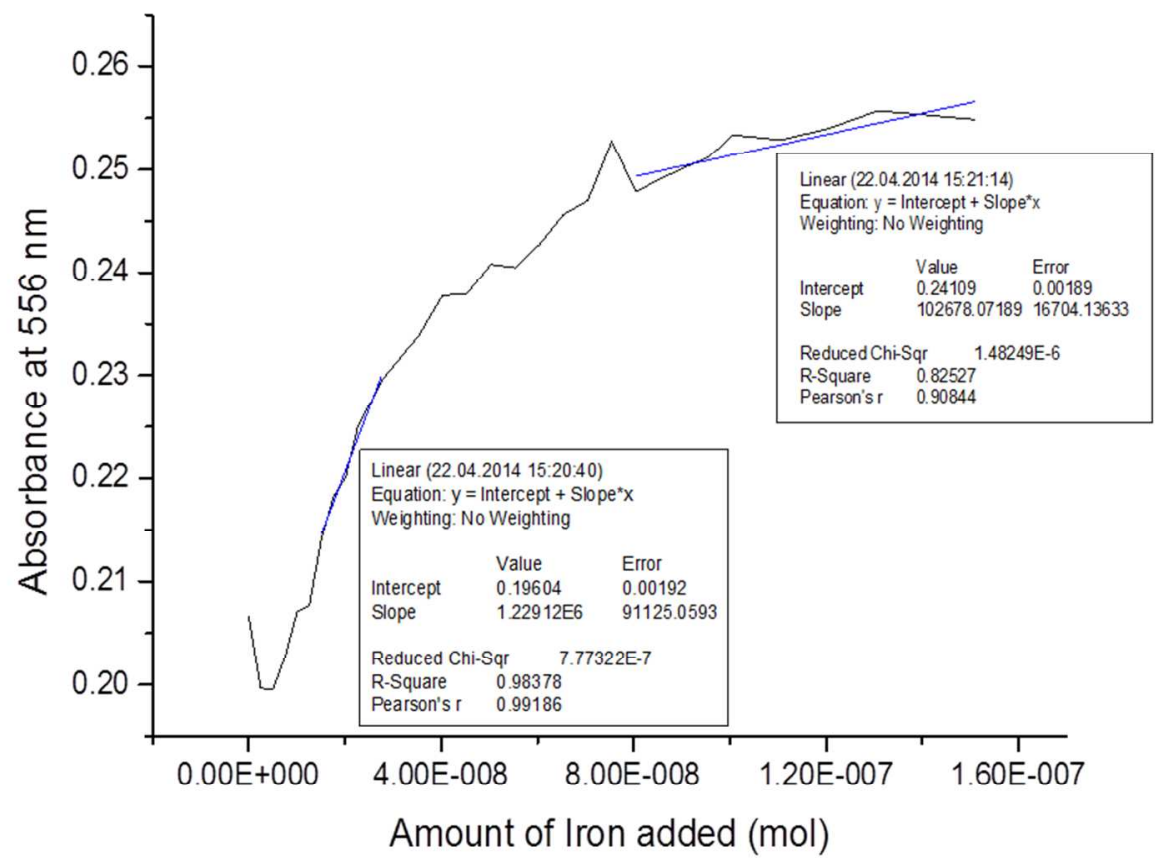


Figure S-4. Absorbance at $556 \mathrm{~nm}$ vs. Fe(II) concentration used for the quantification of TP1 covalently attached to the membrane.

\section{Volumetric degree of swelling measurement}

All dimensions were determined with a Mitutoyo 522 Diamond Master Vernier. A membrane was dried in the desiccator over molecular sieves for one day. Afterwards, its volume $\left(\mathrm{V}_{0}\right)$ was determined by measuring the side lengths and the thickness. Then the membrane was placed into water or hexane for 24 $\mathrm{h}$ and the volume $\left(\mathrm{V}_{1}\right)$ was measured again. Each measurement was repeated three times. The volumetric degree of swelling $\mathrm{S}$ was calculated using the following formula:

$S=\frac{V_{1}}{V_{0}}$

- Swelling degree in water

- Swelling degree in hexane

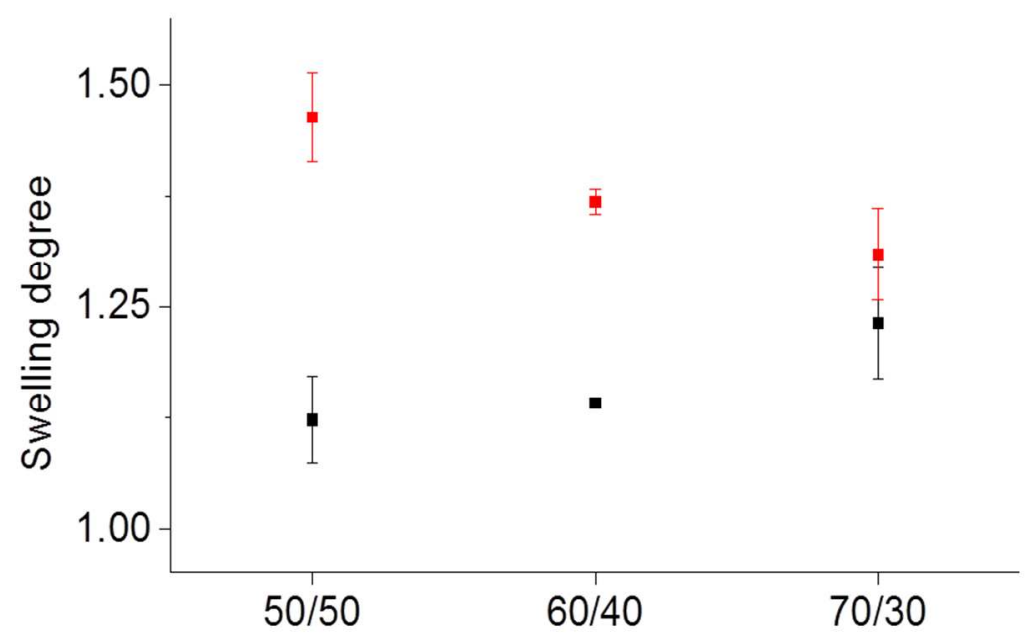

Figure S-5. Swelling degree of APCNs in water and hexane at different ratio between 2-

((trimethylsilyl)oxy)ethyl acrylate (TMS-HEA) and $\alpha, \omega$-methacryloxypropyl poly(dimethylsiloxane) (PDMS-DMA) all of them functionalized with 0.4 wt.- $\%$ of TP1.

\section{Influence of TP1 on permeability and degree of swelling}




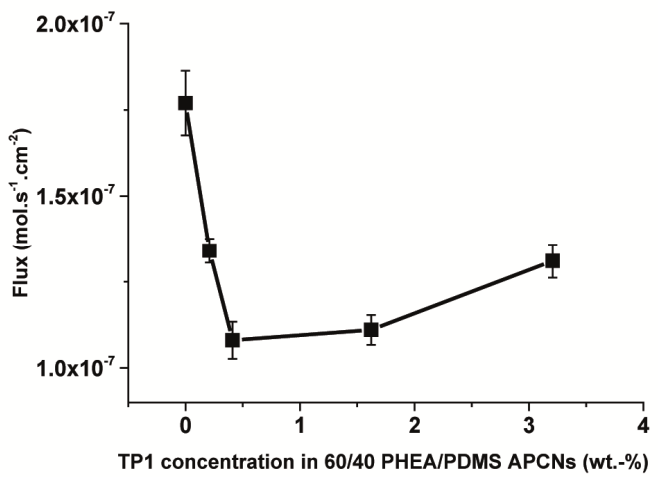

A

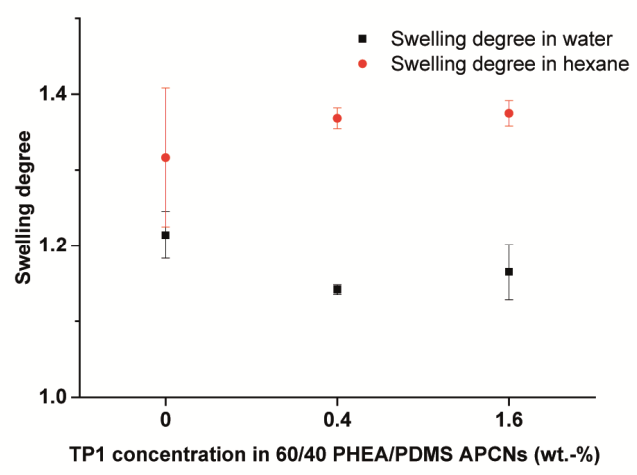

B

Figure S-6. Variation of permeability of caffein (A) and swelling degree (B) of APCNs membrane at TMS-HEA/PDMS ratio of 60/40 functionalized with different amounts of TP1.

\section{XPS measurements}

XPS measurements (PHI 5600 spectrometer) were done using non-monochromatized Mg-Ka radiation $(1253.6 \mathrm{eV})$ and operated at $300 \mathrm{~W}$. The operating pressure of the XPS analysis chamber was approximately $1.10^{-8}$ Torr. The spectra were collected at photoemission angles of $45^{\circ}$ with respect to the surface normal. The relative sensitivity factors of 0.314 for $\mathrm{C} 1 \mathrm{~s}, 0.733$ for O1s, $0.368 \mathrm{Si} 2 \mathrm{p}, 0.499 \mathrm{~N} 1 \mathrm{~s}$ and 1.964 for $\mathrm{Fe} 2 \mathrm{p}_{3 / 2}$ have been used for quantification.

Table S-1. XPS analysis of APCNs membrane (60/40 TM-HEA/PDMS) with 1.6 wt-\% TP1

\begin{tabular}{|c||c|c||c||c||c||}
\hline \multirow{2}{*}{ Name } & Bonds & $\begin{array}{c}\text { Position } \\
\mathbf{( e V})\end{array}$ & Area & $\begin{array}{c}\text { \% Conc. } \\
\text { found }\end{array}$ & $\begin{array}{c}\text { \% Conc. } \\
\text { theory }\end{array}$ \\
\hline \hline C 1s & $\mathrm{C}-\mathrm{C}, \mathrm{C}-\mathrm{H}$ & 284.99 & 4881.2 & 40.02 & 40.39 \\
\hline \hline C 1s & $\mathrm{C}-\mathrm{C}, \mathrm{C}=\mathrm{C}$ & 286.11 & 1517.5 & 12.44 & 13.66 \\
\hline \hline C 1s & $\mathrm{C}=\mathrm{O}$ & 289.06 & 210.0 & 1.72 & 6.24 \\
\hline O 1s & $/$ & 533.08 & 6817.4 & 23.94 & 28.84 \\
\hline \hline Si 2p & Si-O & 102.29 & 3060.5 & 21.41 & 10.63 \\
\hline \hline N 1s & N in organic matrix & 400.44 & 89.78 & 0.46 & 0.24 \\
\hline
\end{tabular}




\section{Characterization of APCNs functionalized with TP1 and SP}

\section{Optical properties}

UV spectra were recorded with a Lambda 9 spectrometer (Perkin Elmer) in the transmission mode. The UV irradiation experiments were carried out with a UV-light source (intraLED UV Volpi, $386 \mathrm{~nm}, 1.5$ $\mathrm{mW} . \mathrm{cm}^{-2}$ ) or withthe white light source intraLED 3 from Volpi (400-700 nm, 500 lumen). After illuminating the membrane for $1 \mathrm{~min}$ with white light, the spectrum of the membrane was measured between 200 and $800 \mathrm{~nm}$. Subsequently, the membrane was illuminated for 1 min with UV light and the spectrum was measured again. Three APCN membranes with $0.4 \mathrm{wt}-\%$ of TP1 and $1.0 \mathrm{wt}-\%$ SP were analyzed: One uncomplexed, one complexed in $\mathrm{CoCl}_{2}$ and one in $\mathrm{FeCl}_{2}$.

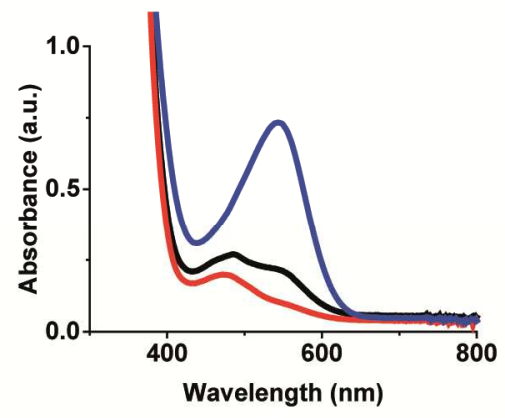

A

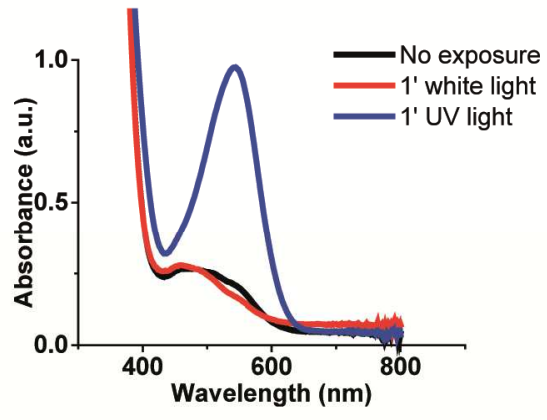

$B$

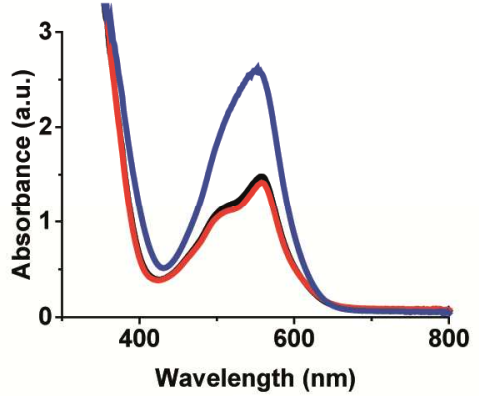

C

Figure S-7. UV-Vis profiles before and after light switch of spiropyran units (SP) for APCNs functionalized with $0.4 \mathrm{wt}-\%$ of TP1 and $1.0 \mathrm{wt} .-\%$ of SP A) in the absence of metal ions, B) in presence of $\mathrm{CoCl}_{2}$ and $\mathrm{C}$ ) in the presence of $\mathrm{FeCl}_{2}$.

\section{Degree of swelling and contact angle:}

Contact angles of the membranes were measured using a Krüss DSA25 device. They specimen were previously dried in a desiccator over molecular sieves for $18 \mathrm{~h}$. The value given is an average over ten measured membranes. 


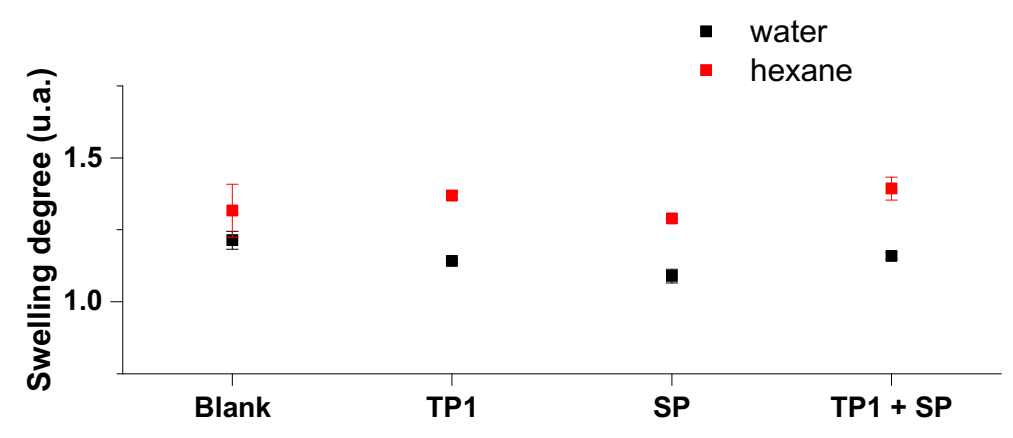

A

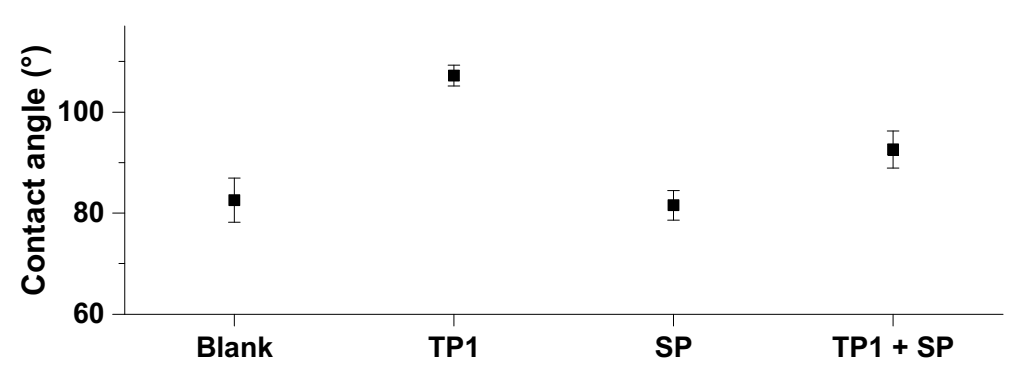

B

Figure S-8. A) Swelling degree in water ( $\mathbf{})$ and hexane ( $\square$ ) and B) contact angle in water of APCNs membrane PHEA/PDMS 60/40 without any functionalization (blank), APCNs functionalized with 0.4 wt$\%$ of TP1, APCNs functionalized with $1.0 \mathrm{wt}-\%$ SP only and APCNs functionalized with 0.4 wt- $\%$ of TP1 and 1.0 wt.- $\%$ of SP.

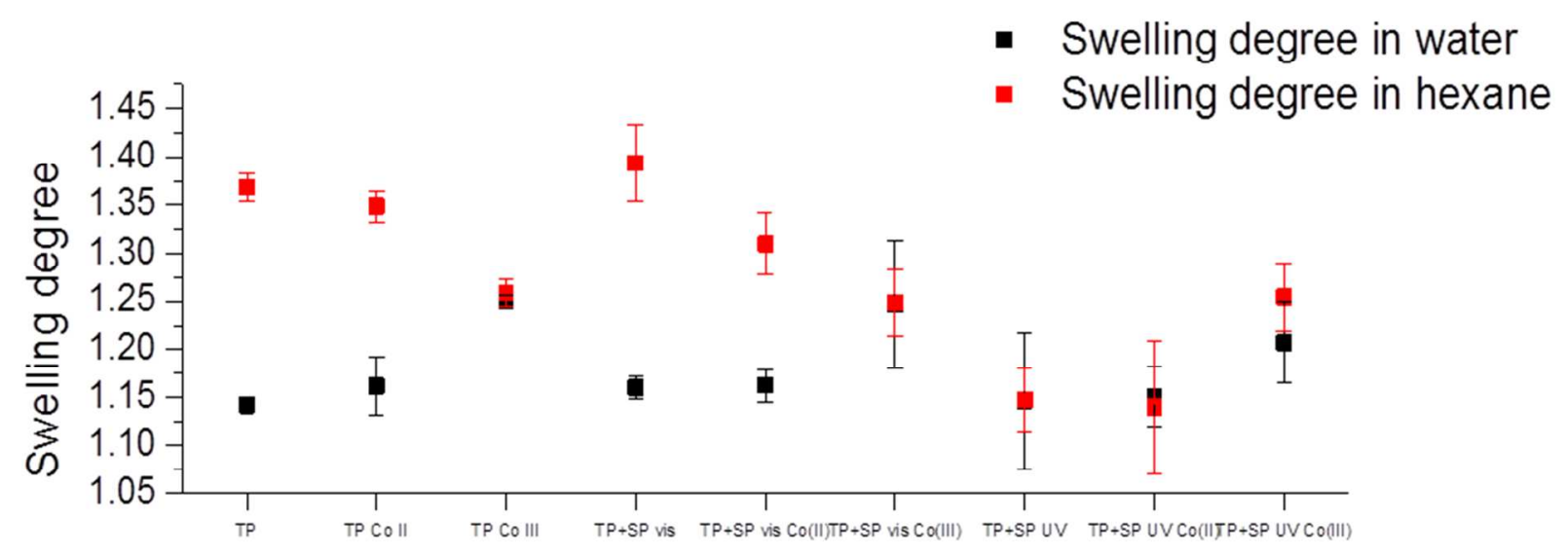




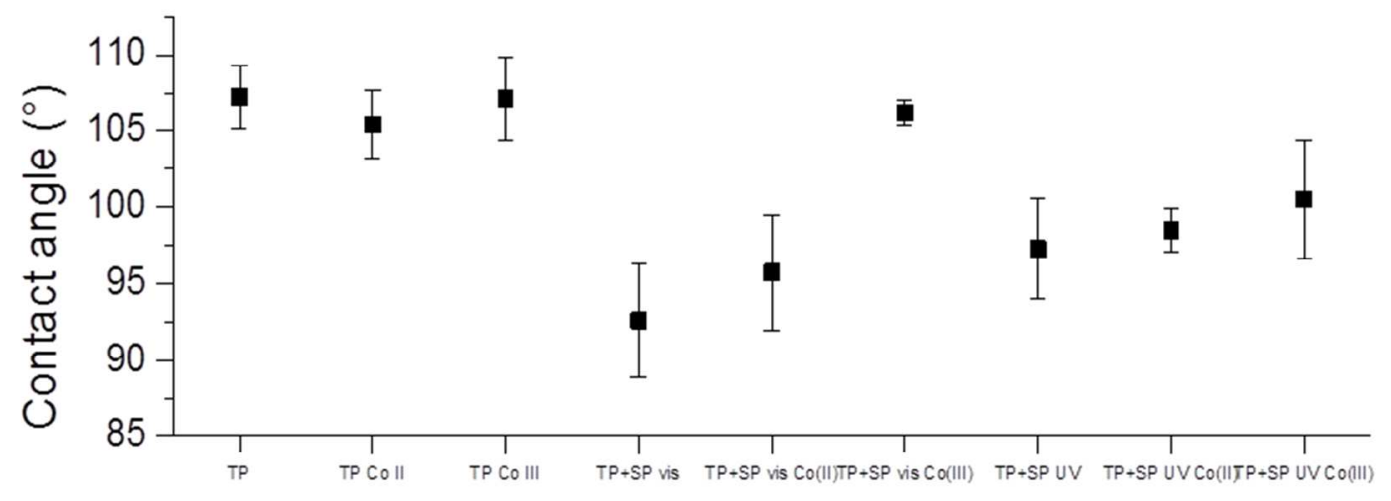

$\mathrm{B}$

Figure S-9. A) Swelling degree in water ( $\square$ ) and hexane ( $\square$ ) and B) contact angle in water of APCNs membranes PHEA/PDMS 60/40 functionalized with 0.4 wt-\% of TP1 (TP in the Figure), complexed with $\mathrm{Co}(\mathrm{II})$ or $\mathrm{Co}$ (III) in the absence and in the presence of $1 \mathrm{wt} .-\%$ of SP in the merocyanine form (SP vis) and in its spiropyran form (SP UV).

1 L. Baumann, D. de Courten, M. Wolf, R. M. Rossi and L. J. Scherer, ACS Appl. Mater. Interfaces, 2013, 5, 5894-5897.

2 L. Baumann, K. Schöller, D. de Courten, D. Marti, M. Frenz, M. Wolf, R. M. Rossi and L. J. Scherer, RSC Adv., 2013, 3, 23317-23326.

3 S. Bode, L. Zedler, F. H. Schacher, B. Dietzek, M. Schmitt, J. Popp, M. D. Hager and U. S. Schubert, Adv. Mater., 2013, 25, 1634-8.

4 E. C. Constable, K. Harris, C. E. Housecroft, M. Neuburger and S. Schaffner, Chem. Commun., 2008, 5360-2.

5 H. S. Chow, PhD thesis, 2005 URL: edoc.unibas.ch/194/1/DissB_7029.pdf. 
Page 37 of 37

Page 37 of 37

(2)

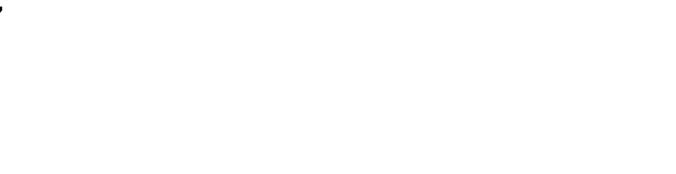

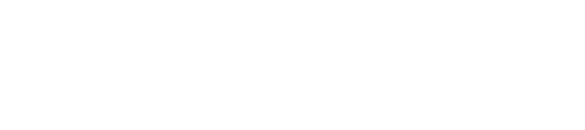

